\title{
EL CARÁCTER NARRATIVO DEL DOCUMENTO Q
}

\author{
José Colinas Blanco \\ Universidad Pontificia de Salamanca \\ jcolinasgallojr@hotmail.com
}

Resumen: Siguiendo las investigaciones más recientes sobre el Documento Q, este artículo muestra el carácter narrativo de esta obra, a diferencia de otras aproximaciones más tradicionales, que lo abordaban como una mera colección de discursos. Para hacerlo se estudian los elementos clave que configuran una trama bien articulada y que permiten concluir que Q es mucho más que una colección de dichos de Jesús.

Palabras clave: Documento Q. Intriga narrativa. "El que ha de venir" (ho erjómenos). Cristología. Dichos de Jesús.

Titel: The narrative Character of Document "Q".

Abstract: Following the most recent research on Document Q, this article shows the narrative character of this work facing a more traditional approaches that looked at it as collection of sayings. To do this the Author studies the key elements that make up a well articulated plot and which allow to conclude that Q is much more than a collection of sayings of Jesus.

Keywords: Document Q. Narrative Plot. "The One is Coming” (ho erjómenos). Christology. Sayings of Jesus. 
El carácter hipotético de Q genera una serie de límites y dificultades para su estudio que no siempre son fáciles de solventar. El primero de todos está relacionado con su existencia, algo no aceptado por todos los exegetas $^{1}$. Sin embargo, al hablar de Q no tratamos con una teoría marginal o menor en el mundo de la exégesis; son más de ciento cincuenta años de estudios sobre ella que no solo han arrojado abundante luz sobre el campo de las ciencias bíblicas, sino que también nos han hecho conocerla mejor. Por eso creo, junto a otros muchos, que la existencia de Q es la mejor manera de explicar el llamado "problema sinóptico", y que los estudios sobre ella nos llevan a una mejor comprensión de la figura del mismo Jesús ${ }^{3}$. Fruto de esa convicción ha sido el trabajo personal de estos últimos años, parte de cuyo fruto se recoge en estas páginas ${ }^{4}$. Desde mi punto de vista, trabajar sobre Q es de vital importancia para el mundo de los estudios neotestamentarios, porque da acceso a un período de la tradición anterior a los evangelios, a la visión de unas comunidades testigos de la mayor parte de la misión de Jesús, en definitiva, a un "producto textual único de las primeras décadas del cristianismo"5.

A lo largo de estos últimos años se ha ido consolidando la teoría de que $\mathrm{Q}$ fue un documento escrito. Tampoco esta es una cuestión superflua; de ser así, tenemos ante nosotros una obra que recoge algunas de las enseñanzas más bellas y capitales del cristianismo, como las bienaventuranzas, el Padrenuestro, el relato de las tentaciones, etc.; estas y otras muchas enseñanzas de Jesús fueron las que causaron que un grupo de sus discípulos quisiera conservar su memoria, constituyendo para ellos un fiel reflejo de la vida de su Maestro ${ }^{6}$. La hipótesis de una fuente escrita da pie a estudiar también la forma escogida para guardar los recuerdos sobre Jesús y ver cómo se va construyendo la memoria sobre él.

1 Goodacre, The Case Against Q. El argumento central que defienden este y otros autores que van en esta línea es que la relación de dependencia entre los sinópticos es suficiente para explicar el material de doble tradición y, por tanto, se hace innecesario recurrir a un "ente" del que no se conserva ninguna prueba para explicar lo que puede hacerse de otra manera.

2 Para una información más detallada sobre la historia del "problema sinóptico" remito a la obra de GUIJARRO OPORTO, Los cuatro evangelios.

3 Una presentación convincente que apoya la existencia de $Q$ la podemos encontrar en TUCKETT, "The Existence of Q".

${ }^{4}$ Colinas blanco, ó é $\rho \chi o ́ \mu \varepsilon v o c$.

5 Hurtado, Señor Jesucristo.

6 Álvarez Cineira, “El Documento Q". 


\section{Los precedentes: $Q$, de "colección de dichos" a narración}

Desde que comenzaron los estudios sobre Q, allá por el siglo XIX, hasta la fecha se ha ido produciendo un cambio entre los exegetas en relación con cómo debe considerarse este material. El principal de todos, a mi juicio, ha sido pasar de acercarse a Q "solo" como fuente sinóptica a estudiarla como documento escrito dotado de una cierta estructura. No es objeto de este artículo recoger cómo se ha ido produciendo esta evolución. Sin embargo, dado que el método que voy a utilizar es el análisis narrativo, considero necesario justificar que esta forma de estudiarla cuenta con un apoyo sólido.

El primero que señaló la existencia de algunos indicios de cohesión en Q que dan a la obra cierta unidad, y que también sirven para justificar su carácter narrativo, fue A. D. Jacobson. Sus primeras aproximaciones vieron la luz en forma de artículo ${ }^{7}$, pero ulteriores investigaciones dieron como fruto una monografía que se ha convertido en todo un clásico sobre $\mathrm{Q}^{8}$. Más tarde, J. S. Kloppenborg hizo una aportación muy significativa al demostrar que, en Q, al igual que en Marcos, podemos detectar la presencia de "progresiones narrativas lógicas"9 (o "estructuras redaccionales mayores de Q", como las denomina en una obra posterior ${ }^{10}$ ) cuya finalidad es hacer que la narración avance. De modo similar, H. T. Fleddermann, al hablar de las características literarias de Q, se refiere a ellas como los "patrones léxicos" que unen las distintas perícopas ${ }^{11}$.

Un paso más allá fue D. C. Allison Jr., quien defiende la existencia de una unificada estrategia composicional en $\mathrm{Q}^{12}$; de igual manera, S. Guijarro, al hablar de la unidad literaria del Documento Q, señala que existen algunos temas que cohesionan las diversas agrupaciones de dichos ${ }^{13}$. En esta línea también está el estudio de R. Uro ${ }^{14}$. Quizá la aportación que más tiene que ver con lo que pretende el presente artículo ha sido la de I. Park, en una de las últimas obras escritas sobre este tema, al hablar de la existen-

7 JACOBSON, "The Literary Unity of Q".

8 JaCOBSON, The First Gospel.

9 KLoppenborg, The Formation of Q, 104-108.

10 KLoppenborg, Excavating Q, 118-124.

11 Fleddermann, Q: A Reconstruction.

12 Aluison JR., The Jesus Tradition, 11-15.

13 Guijarro Oporto, Los dichos de Jesús, 33.

14 URo, “John the Baptist", 240. 
cia de una trama en Q, aunque no se recurre al mismo método que este estudio para sacar sus conclusiones ${ }^{15}$.

Este pequeño recorrido histórico señala la cercanía de Q al género narrativo. Por tanto, la aplicación del análisis narrativo se sitúa en línea de continuidad con lo anterior, pero buscando ir un paso más allá. Pretendo mostrar que existen en $\mathrm{Q}$ algunos de los elementos que caracterizan a la literatura narrativa, y, desde ahí, probar que en él se dan las características propias de una narración. Todo ello con la certeza de que esto nos iluminará para lograr un mejor conocimiento de $\mathrm{Q}$.

Otra aclaración que considero necesaria hacer al comienzo de este estudio es señalar que el material con el que vamos a trabajar es la última edición crítica que se ha realizado sobre el Documento $\mathrm{Q}^{16}$. En la introducción a esta obra vienen explicados detalladamente los criterios y procedimientos que han servido para su elaboración ${ }^{17}$. La publicación de esta reconstrucción supone un paso importante en los estudios sobre el Documento Q, porque permite que sea abordado como una realidad palpable y disponible y no ya solo como una mera hipótesis. Es evidente que su alcance no es comparable al de las ediciones del Novum Testamentum Graece de NestleAland, pero evidencia que $\mathrm{Q}$ no está irremediablemente perdido detrás de las mejoras redaccionales de Mateo y Lucas, tal como opinan algunos. Es cierto que, en muchos casos, la redacción original de Q es irrecuperable, al igual que sucede con la mayoría de los textos de la antigüedad; pero actuando de esta manera se asimilan los principios de la crítica textual, que como ciencia trabaja con probabilidades, no con certezas absolutas.

Tenemos, por tanto, un texto tan utilizable como el del NT. En su abordaje habrá que tener las mismas reservas que con cualquier texto reconstruido a partir de fuentes parciales. Lo determinante es que, como

15 PARK, “Children and Slaves", en Roth - Zimmermann - Labahn (eds.), Metaphor, 76.

16 Robinson - Hoffmann - KLoppenborg, The Critical Edition of $Q$.

17 Kloppenborg, Excavating Q, 85. La intuición original que subyace al proyecto de la publicación de la edición crítica de $Q$ es la convicción de que en algún momento de su desarrollo llegó a ser un texto escrito. J. S. Kloppenborg, partiendo del estudio de las perícopas compartidas por Mateo y Lucas, ofrece tres argumentos en esta línea. El primero se asienta en el acuerdo casi literal que existe entre ellas en el orden verbal y en las preposiciones, que son lo más variable de la sintaxis griega. El segundo hace referencia a la coincidencia que hay en la disposición de los dichos, teniendo en cuenta que no existe ningún factor que la sancione como la más adecuada. El tercero se fija en la concordancia verbal en el uso de expresiones poco corrientes, no testimoniadas ni en los LXX ni en otras partes del NT. Ninguno de estos tres elementos podría explicarse satisfactoriamente sin la existencia de una fuente previa ya fijada. 
argumenta S. Guijarro, "se haya podido reconstruir un texto arquetípico que nos permite conocer con más precisión los contornos del Documento Q"18. Tenerlo supone una abstracción útil sobre la que trabajar, que funciona para los estudiosos de Q de la misma manera que ha funcionado para la exégesis moderna la idea del texto crítico del NT, y que posibilita tener acceso a realidades tales como su vocabulario, sintaxis o tendencia teológica.

\section{La trama, "esencia de la narración"}

Existen ciertos elementos que determinan que un texto sea una narración. Estos son los que el autor utiliza para desplegar su estrategia narrativa. Los críticos literarios, sin llegar a un acuerdo sobre su importancia, señalan que todo relato tiene al menos estos cuatro elementos: un narrador, un escenario, unos personajes y una trama o intriga que da cohesión a todo lo anterior.

De todos ellos, el más importante para hablar de la existencia de una narración es la trama o intriga, que, según los narratólogos, es el núcleo del relato, ya que sin ella este no existe ${ }^{19}$. Por trama entendemos la estructura unificadora que enlaza las diversas peripecias del relato y las organiza, asegurando de este modo la unidad de la acción y dando así sentido a los múltiples elementos de la narración. Está basada en una relación de causaefecto, sea por contingencia, probabilidad o necesidad; es decir, desde el momento en que entre dos hechos se sitúa una relación de causalidad podemos hablar de trama. Su finalidad es hacer caer en la cuenta al lector de que la historia es más que un amasijo de incidentes, y así hacerle entrever un guion coherente en aquello que se le está refiriendo.

La trama, como ha señalado P. Ricoeur, tiene dos componentes fundamentales ${ }^{20}$. El primero es el factor cronológico, que da a la trama el carácter narrativo imprescindible para el buen entendimiento de la misma. Esto nos lleva a diferenciar entre "tiempo real" y "tiempo de la narración". El primero siempre corresponde a la duración de los acontecimientos y acciones en la historia, y está medido en unidades temporales (horas, días,

18 Guijarro Oporto, Los dichos, 23.

19 Marguerat - Bourquin, Cómo leer, 33. Aquí se dice que, para poder decir que un texto es un relato, se necesita que haya: una sucesión temporal de acciones y acontecimientos; la presencia de un agente-héroe que tenga una intención, que lleve el relato a un fin; una trama que dé unidad a la acción y una relación causaefecto que estructure esa trama.

20 Ricoeur, Para una teoría, 127. 
años...); el segundo es el tiempo material necesario para contar el discurso concreto, y su duración se corresponde con la amplitud del relato y se mide en palabras, frases, párrafos... Esta diferenciación nos permite ver las decisiones que el narrador ha tomado para producir algunos efectos, tales como alteraciones del orden cronológico, entrelazamiento de hilos narrativos y velocidad de la narración ${ }^{21}$.

El segundo elemento, el suspense o intriga, se refiere a las transformaciones o cambios que se van dando en la narración, ayudando al progreso de la trama y captando la atención del lector. Esta tensión narrativa o intriga se manifiesta de tres formas diversas y complementarias: el suspense (ocultar al lector cómo continua el relato), la curiosidad (eliminar algún elemento para conseguir que el lector no entienda completamente la narración y siga atento a ella) y la sorpresa (el descubrimiento por el lector de algo que le ha sido ocultado y que le hace cambiar su modo de comprender la historia). La intriga resulta ser entonces el mecanismo por el que el lector entra en el movimiento del relato. Puede clasificarse en dos grandes categorías con dos modelos cada una: intriga unificadora o episódica (dependiendo de si todos los episodios son necesarios para la comprensión del relato o de si el lector puede saltar de uno otro, es decir si no necesita el conocimiento previo del anterior para comprender un episodio en concreto) e intriga de resolución o de revelación (dependiendo de si el tiempo, la evolución y el orden de los acontecimientos son esenciales para la historia o de si los acontecimientos tienen una función ilustrativa, subordinada al personaje $)^{22}$. Normalmente, estas intrigas no se dan por separado, sino que lo más frecuente es encontrarlas combinadas en la narración.

Otro punto importante es saber cómo se articula la trama que está constituida de diversas partes ${ }^{23}$. En primer lugar está la exposición, que consiste en presentar el estado de la cuestión antes de que la acción comience. Suele proporcionar al lector informaciones básicas y breves (respecto al marco narrativo, los personajes y sus relaciones...) y a veces también la clave para comprender el relato. No es fácil de delimitar, porque a veces engloba dentro de sí otro elemento de la trama que es el momento desencadenante de la acción, responsable de la tensión dramática, el suspense y las

21 Estas se agrupan dentro de cuatro categorías con gran repercusión semántica en cuanto a su contribución en la construcción del relato: analepsis, prolepsis, lagunas y elipsis, ver MARguerat - Bourquin, Cómo leer, 145-150.

22 Ib., 90-91.

${ }^{23}$ Ska, Nuestros padres, 22-32. Aquí se puede encontrar más desarrollado este modelo explicativo. 
expectativas, instante en el que la atención del lector es atrapada por el relato. Después tenemos la complicación, que se corresponde con el "nudo" y se refiere al intento o los diversos intentos por resolver el problema o conflicto planteado. Esta es la etapa donde verdaderamente se produce la "tensión narrativa", que equivale a la pregunta que el lector se hace en su fuero interno sobre lo que va a suceder ${ }^{24}$. Luego está el clímax o giro de la acción, momento en que la tensión se colma y que constituye la etapa final del progreso narrativo. En consecuencia, es el elemento que conduce al relato a la conclusión y que a veces coincide con la resolución que pone fin al suspense del relato ${ }^{25}$. Finalmente tenemos la conclusión, donde encontramos el resultado y las consecuencias de la resolución, epílogo de la historia donde la tensión y el suspense desaparecen ${ }^{26}$.

Pienso que la revelación de la existencia de una trama o intriga en Q es clave para decidir si se puede hablar de ella como una obra con un "cierto" carácter narrativo ${ }^{27}$. Pero antes de continuar con el trabajo creo importante hacer una aclaración. El esquema anteriormente expuesto es un esquema "tipo" que no se puede aplicar sin más a los textos. Valga como ejemplo que la distinción entre las distintas etapas no es siempre evidente (la distinción entre clímax, giro de la acción y resolución está cuestionada por bastantes autores) y que estos diversos momentos no siempre están

${ }^{24}$ Ib., 63: "La tensión narrativa sume al lector en un estado de espera e incertidumbre hasta el desenlace, que se vincula a la pregunta: ¿cómo se ha llegado hasta aquí?"

25 Ib., 29. Las dos formas de resolución son la inversión, que es el paso de un estado a su opuesto, y la revelación, que es el paso de la ignorancia al reconocimiento; ambas se corresponden con la intriga de resolución y revelación respectivamente.

${ }^{26}$ SKa - Sonnet - WenIn, Análisis narrative, 26. "Tratándose del relato bíblico, inversión y reconocimiento son más que técnicas narrativas; participan de la experiencia de Dios. En efecto, el mundo bíblico es un mundo de revoluciones, es un lugar de sorpresas extraordinarias, pues su Dios es el de las inversiones, que se reconocen no en la modificación progresiva, sino en el cambio radical. Al hacer esto, el relato bíblico otorga un estatuto teológico a uno de los resortes más poderosos del arte narrativo".

27 Esta expresión y otras como "tendencia narrativa" o "tono narrativo" pueden parecer a primera vista expresiones algo ambiguas. Siempre que aparecen en el texto quieren expresar mi convicción, siguiendo la estela de muchos otros autores, de que el Documento $Q$ está más próximo al género literario narrativo de los evangelios canónicos que al género discursivo representado por el Evangelio de Tomás. A mi parecer, la pretensión del redactor final era construir una obra de estilo biográfico sobre Jesús, y de ahí que las decisiones que toma van encaminadas a la consecución de dicho fin. Por eso la aplicación de las herramientas del análisis narrativo es un enfoque fructífero para comprender mejor este texto. 


\section{EL CARÁCTER NARRATIVO DEL DOCUMENTO Q}

presentes en los textos particulares. Por eso creo conveniente tomar una opción antes de comenzar a analizar narrativamente el Documento Q. Asumo la postura de los que sostienen que los elementos necesarios para la construcción de trama, de los que un relato no puede prescindir, son la acción transformadora, que siempre debe estar presente, aun cuando sea evocada y no descrita; el nudo, que se corresponde con los diversos intentos de resolver el conflicto planteado; la situación inicial, que también puede ser evocada; y, finalmente, el desenlace y la situación final, que deben estar presente, al menos uno de los $\operatorname{dos}^{28}$. Si esto se halla en Q, como creo que es el caso, entonces se puede sostener la hipótesis de este artículo, es decir, que al tener una trama estamos legitimados para hablar del carácter narrativo de $\mathrm{Q}^{29}$.

\section{La narratividad del Documento Q}

Como el contenido principal de Q son palabras de Jesús, ha sido y sigue siendo conocida como "fuente de dichos Q" o también la más audaz designación de "evangelio de dichos Q" ${ }^{30}$. Esta forma de denominarla ha hecho que haya sido comparada con otras obras de contenido similar, como el Evangelio de Felipe y, sobre todo, con el Evangelio de Tomás ${ }^{31}$. Siendo cierta esta similitud, algunos exegetas ya notaron que existe una gran diferencia; y es que la presencia de elementos narrativos en Q la asemejan más a los evangelios canónicos que al de Tomás ${ }^{32}$. Esto ha supuesto que, en las

28 Marguerat - Bourquin, Cómo leer, 78.

29 A esto hay que añadir que esta tarea tiene un mayor grado de dificultad en $Q$. Es esta una composición compleja que utiliza materiales precedentes y los incorpora; debido a ello, a la hora del análisis de la macroestructura, el fin prioritario no es ver cómo todo encaja dentro de lo que se considera la estructura estándar de un relato, como si partiéramos del a priori de que el Documento $Q$ lo fuera, sino que lo principal será señalar aquellos indicios seguros donde nos podemos apoyar para ver esas características narrativas, sobre todo la intriga que crea la trama, y así ver si al final podemos suscribir las afirmaciones de aquellos autores que abogan por su carácter narrativo o que defienden que $Q$ es una narración de pleno derecho.

${ }^{30}$ Cf. Robinson, “The Saying Gospel Q"; Jacobson, The First Gospel; KloppenBorg, Excavating Q; NeIRYNCK, “Q: From Source to Gospel”.

31 Cf. de Santos Otero, Los evangelios apócrifos. Para un estudio comparativo entre el Evangelio de Tomás y el Documento Q, véase McLEAN, “On the Gospel”. El Evangelio de Tomás está formado por 114 dichos de Jesús dirigidos a sus discípulos e introducidos en su mayor parte por la fórmula "dijo Jesús" (ho lēsous eípen).

32 Williams, "Parable and Chreia"; Downing, "Quite Like Q". 
últimas décadas, se haya hecho un notable esfuerzo en ahondar en esta intuición, llegando a afirmarse no solo que en el Documento Q hay una clara tendencia hacia la narratividad ${ }^{33}$, sino que $\mathrm{Q}$ sería propiamente un relato, porque contiene todos los elementos que son propios del mismo ${ }^{34}$. De ahí, pienso con otros autores, que, para comprenderlo mejor, no es solo plausible, sino incluso necesario, aproximarse a $\mathrm{Q}$ desde una perspectiva narrativa ${ }^{35}$.

\subsection{Tradiciones de carácter narrativo en el Documento $Q$ y su función}

Dentro de los elementos narrativos que pueden encontrarse en el Documento Q tenemos tres tipos de tradiciones: jreias o apotegmas, parábolas y un breve relato. El argumento para identificarlas como narrativas es el mismo que sostienen los narratólogos: debe existir una cierta trama o intriga, que es esencial para afirmar que un texto es narrativo ${ }^{36}$.

Las jreias son palabras de Jesús que fueron encapsuladas para su conservación dentro de un sencillo marco narrativo, dando con ello lugar a una pequeña escena. Fijémonos a modo de ejemplo en la de Q 7,18-23. En esta escena, unos discípulos de Juan Bautista se acercan a Jesús y le formulan una pregunta: “¿Eres tú el que ha de venir o debemos esperar a otro?” $(\mathrm{Q} 7,18-19)^{37}$. Esta cuestión hace referencia al anuncio de Juan Bautista con que se abre el Documento (Q 3,16b). Jesús responde con una enumeración de sus acciones: "Id a contar a Juan lo que estáis viendo y oyendo: los ciegos recobran la vista, los cojos caminan, los leprosos son purificados, los sordos oyen, los muertos resucitan y a los pobres se les anuncia la buena noticia" $(\mathrm{Q} 7,22)^{38}$, y cierra la perícopa un macarismo: "Dichoso el que no se escandaliza de mín" (Q 7,23). La intriga se manifiesta en primer lugar como suspense en la pregunta de los emisarios y, en segundo lugar, en forma de curiosidad, ya que Jesús no afirma ni desmiente que él es "el

33 Cf. Robinson, “The Saying Gospel Q”, 375.

34 Fleddermann, Q: A Reconstruction, 106.

35 Fleddermann, "The Plot of Q", 68.

36 Cf. Marguerat - Bourquin, Cómo leer, 67.

37 Bultmann, Historia, 83.

38 Cf. Chatman, Story, 45. El autor sostiene que los principales tipos de acción que dan forma a un personaje son actos físicos no verbales, discursos, pensamientos y sentimientos, percepciones y sensaciones. De ahí que "anunciar la buena noticia a los pobres" $(Q 7,22)$ pueda ser considerada una acción de Jesús. 
que ha de venir" anunciado por Juan. Podría añadirse que, en la respuesta de Jesús, se da también el componente de sorpresa, por la cual el lector es invitado a cambiar su modo de comprender a Jesús, como bien queda reflejado en Q 7,23. Lo mismo sucede con otros materiales de similar orientación (Q 4,1-13; 6,47-49; 9,57-60; 13,18-21) ${ }^{39}$.

Este carácter narrativo no solo concierne a tradiciones puntuales, sino que es un fenómeno también verificable en la estructura interna del Documento Q, uno de sus aspectos más trabajados. Partiendo de la propuesta de Kloppenborg, que adopta en mayor o menor medida la mayoría de los investigadores ${ }^{40}$, observamos cómo algunos de los bloques que conforman Q están introducidos por una tradición de carácter narrativo que aporta esta perspectiva a toda la sección que les sigue ${ }^{41}$. En la perícopa Q 9,57-60, por ejemplo, se dice: "Uno le dijo: 'Te seguiré adonde quiera que vayas'. Y Jesús le dijo: 'Las zorras tienen madrigueras y los pájaros del cielo, nidos, pero el Hijo del hombre no tiene donde reclinar la cabeza'. Otro le dijo: 'Señor, permíteme que vaya primero a enterrar a mi padre'. Y él le dijo: 'Sígueme y deja que los muertos entierren a sus propios muertos". La escena no solo sirve como marco narrativo a dos sentencias de Jesús, sino que introduce un bloque de enseñanzas a sus discípulos. La colocación de esta jreia al comienzo tiene la intención de situarlo narrativamente. Esto se logra de dos maneras; por un lado, introduce las enseñanzas de Jesús a sus discípulos en el marco de una escena -un encuentro entre Jesús y unos pretendientes al discipulado-. Por otro, las sitúa dentro del ámbito de la actuación de Jesús, de quien se dice que tuvo discípulos a los que preparó, envió a misionar y enseñó a orar (Q 9,57-11,13). Así, su ubicación hace que no solo la unidad tradicional (Q 9,57-60), sino todo el bloque del que forma parte, quede bajo el efecto de la intriga, porque se suscita la curiosidad sobre lo que sucederá después, creando suspense en torno a lo que acontecerá a los discípulos tras ser aleccionados y enviados a desempeñar su misión. Esto requiere una respuesta para comprobar el éxito o fracaso de su tarea. Por eso la jreia también sitúa narrativamente la unidad dentro una trama mayor.

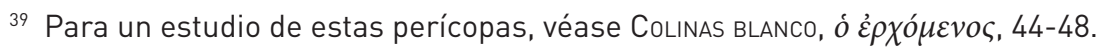

${ }^{40}$ Cf. Kloppenborg, The Formation, 92. El autor muestra cómo los dichos en el Documento no están dispuestos de una manera aleatoria, sino que guardan un cierto orden entre ellos y forman bloques o unidades.

${ }^{41}$ Cf. BaBut, Un tout autre, 303. 


\subsection{La narratividad en el macrotexto}

Los datos anteriores apoyan la hipótesis del carácter narrativo del Documento Q. Sin embargo, ellos solos no bastan para afirmarlo con rotundidad y se hace necesario postular y descubrir la existencia de una trama que vertebre el conjunto de la obra. Como ya advertí, la dificultad de esta tarea es grande debido a la complejidad y naturaleza del material predominantemente discursivo; por eso, lejos de buscar que todo encaje, voy a fijar la atención en aquellos pasajes donde aparecen rasgos que, a mi juicio, son netamente narrativos.

\subsubsection{Presentación de Juan y Jesús ${ }^{42}$}

\section{$Q 3,2 b-17$}

2b Juan [...] ${ }^{43}$ 3a toda [...] la [...] región [...] del Jordán ${ }^{7}$. Dijo a la gente que venía a ser bautizada: "Raza de víboras, ¿quién os advirtió para huir de la cólera que se acerca? ${ }^{8}$ Dad, pues, un fruto digno de conversión y no os gloriéis diciendo en vuestro interior: 'Tenemos por padre a Abrahán'. Porque os digo que Dios puede sacar de estas piedras hijos de Abrahán. 9. Ya está puesta el hacha junto a la raíz de los árboles. Y todo árbol que no dé fruto será cortado y arrojado al fuego". ${ }^{16 b}$ "Yo os bautizo con agua, pero el que ha de venir detrás de mí es más fuerte que yo. Él os bautizará con Espíritu Santo y fuego. ${ }^{17}$ Tiene su bieldo en la mano y aventará su parva y reunirá el trigo en su granero, pero la paja la quemará en un fuego que no se apaga" 44 .

Todo relato debe tener una "situación inicial" que proporcione al lector los elementos necesarios para comprender la situación que el relato va a modificar. En este caso engloba también el "momento desencadenante"

42 Los títulos que encabezan las distintas partes de $Q$ están tomadas de la obra de Guijarro Oporto, Los dichos, 155-178.

43 Es interesante notar que la acción que da el sobrenombre de "Bautista" a Juan pasa a un segundo plano ante su anuncio de la llegada del juicio y su llamada a la conversión. Tampoco hay rastros aquí de la predicación moral de Juan que conservamos en otras fuentes (Lucas y Flavio Josefo), y eso que estas ilustrarían muy bien el contenido de la conversión ("dad buenos frutos") a la que Juan invita. Esto hace pensar que el papel de Juan en $Q$ es el de profeta escatológico (como se confirmará más adelante, en $Q 7,24-28$, donde además se ratificará que es el último de los enviados por Dios antes del envío de Jesús).

44 La traducción está tomada de Robinson - Hoffmann - Kloppenborg, El Documento $Q$. Aquí puede verse el texto griego reconstruido del Documento $Q$ y su traducción al español. 
del conflicto, que se va a tratar de solucionar en el devenir del texto. Así, el anuncio de Juan no solo es el marco narrativo que sitúa espacio-temporalmente la historia, sino que también introduce la problemática fundamental de la obra, que está relacionada con el juicio y quién lo tiene que llevar a cabo.

El comienzo de Q encaja con los datos históricos que tenemos por otras fuentes del entorno de la predicación, el mensaje y la figura de Juan Bautista $^{45}$. Este aparece en escena en la región del Jordán (Q 3,2b-3), dirigiéndose con duras palabras a la gente que acudía a ser bautizada (Q 3,7). Su predicación está propiciada por la convicción de que la paciencia de Dios se ha agotado ante la impenitencia del pueblo de la alianza. ¿De dónde le viene esta certeza? El relato no lo revela, creando así ya una intriga por medio de la curiosidad; solo se informa del juicio que se va a producir; de ahí que se anuncie que se acerca un juez $(\mathrm{Q} 3,16 \mathrm{~b})$ que será el responsable de cumplir la amenaza que se cierne sobre todo el pueblo $(\mathrm{Q} 3,17)^{46}$.

Para Juan, Israel se ha pervertido totalmente; ha pasado de ser el pueblo elegido, el linaje de Abrahán (Q 3,8), a convertirse en una raza de víboras $(\mathrm{Q} 3,7)$; ¿qué es lo que ha hecho mal el pueblo para provocar la cólera de Dios? Tampoco se dice, por lo que será tarea del lector descubrirlo; solo se manifiesta la situación de perdición en que el pueblo se encuentra, la cual se ha hecho tan intolerable para Dios que, según Juan, le ha llevado a decretar un juicio que se describe con rasgos destructivos (Q 3,9.17); aunque, en su misericordia, Dios concede una última oportunidad que pasa por unos frutos dignos de conversión (Q 3,8.9) ${ }^{47}$.

Ligado al juicio, el mismo Juan revela la llegada de un misterioso personaje: "El que ha de venir" ${ }^{48}$; respecto a esta figura, al menos quedan

45 Cf. MeIer, Un judío marginal. II/I, 57-99.

46 Rollens, "Conceptualizing", 93: “El juicio ha sido mostrado como una clave o metáfora organizativa para la comprensión de la composición del Documento Q". Esto coincide con las opiniones de otros autores, que también consideran el juicio como un elemento transversal en Q: KLopPenborg, The Formation, 102: “La llamada al arrepentimiento, la amenaza de un juicio apocalíptico y la censura a 'esta generación' por su renuencia son los temas formativos y unificadores que recorren toda la obra". KlopPenborg, Excavating Q, 118-122; Miquel PericÁs, “Del movimiento de Jesús", 99. Por eso el tema del juicio será uno de los hilos del relato que va uniendo los episodios entre sí.

47 El esquema deuteronomista que sigue la predicación de Juan nos lleva a pensar que la causa del juicio es la desobediencia de Israel. Así lo indica acertadamente JACOBSON, “The Literary Unity”, 384-385.

48 Traduzco el participio de presente ho erjómenos con este matiz futuro porque me parece más adecuado de acuerdo con la expectativa que se crea en el lector, 
claras dos cosas para el lector. La primera, que no es Juan, puesto que aquel es más fuerte, y que bautizará con Espíritu Santo y fuego, y no con agua, como él (Q 3,16b); y la segunda, que es el encargado del juicio, puesto que arrojará al fuego lo que no es fruto, la paja (Q 3,17). Pero, a pesar de la ominosa amenaza, de nuevo se vislumbra la esperanzadora, puerta que Dios deja abierta: el que dé fruto escapará del fuego, porque la tarea de este juez será recoger el fruto, el trigo, en el granero $(\mathrm{Q} 3,17)$. Por este motivo, el lector puede intuir que esta figura tiene dos papeles: llevar a cabo el juicio contra los que sigan en su contumaz pecado; pero también el narrador parece apuntar que su acción de bautizar con Espíritu $(\mathrm{Q} 3,16 \mathrm{~b})$ está ligada a una cierta posibilidad de salvación para los que den buen fruto (Q 3,9). Pero, aunque ha quedado clara su labor, este anuncio ha creado la intriga por medio del suspense: ¿quién será?, ¿cuándo vendrá?

Parece claro que esta escena se corresponde con el momento de la situación inicial, ya que introduce las temáticas, que, ligadas a las expectativas que el narrador suscita en el lector, serán como hilos que aseguran a la historia una coherencia de conjunto ${ }^{49}$. También se observa cómo se ha dado inicio a la tensión narrativa necesaria en todo relato. Esto se ha logrado por medio del recurso al suspense, porque es inevitable que el lector se pregunte lo que va a suceder a continuación, sobre, por un lado, lo que sucederá con el pueblo de Israel, que vivía en la seguridad causada por su condición de pueblo de la promesa hecha a Abrahán. Ahora, aunque no se describan las causas, esta ha quedado rota y ha desaparecido la garantía que les proporcionaba amparo. Ante la cólera que se acerca, cuya única salida es convertirse y dar buenos frutos, ¿escuchará Israel el aviso de Juan? ¿Explorará otras vías para escapar de esa cólera que se manifestará en el juicio que se acerca o permanecerá resguardándose en la pretendida seguridad que le causa ser "hijos de Abrahán"?

Por otro lado, también uno se pregunta sobre la identidad de "el que ha de venir", cuya llegada anuncia Juan $(\mathrm{Q} 3,16 \mathrm{~b})$. Se revela que su principal tarea es ejecutar el juicio venidero, que consiste en separar la paja del trigo $(\mathrm{Q} 3,17)$ y derramar sobre las personas Espíritu y fuego (Q 3,16b), pero, ¿cómo y cuándo llevará a cabo esa labor?

aunque igualmente se puede traducir, como otros hacen, como "el que viene" o "el que vendrá", Zerwick, El griego del Nuevo Testamento, 157; Delgado Jara, Gramática griega. II, 79.

49 WÉNIN, La historia de José, 13. 


\section{EL CARÁCTER NARRATIVO DEL DOCUMENTO Q}

\section{$Q 3,21-4,13$}

3,21 Jesús [...] bautizado, se abrió el cielo ${ }^{3,22}$ y [...] el Espíritu [...] sobre él [...] Hijo [...] 4,1 Jesús fue llevado [al] desierto por el Espíritu 4,2 [para ser] tentado por el diablo. Y no comió nada durante cuarenta días [...] sintió hambre ${ }^{4,3}$ y le dijo el diablo: "Si eres Hijo de Dios, manda que estas piedras se conviertan en panes". ${ }^{4,4}$ Y Jesús [le] respondió: "Está escrito: No solo de pan vivirá el ser humano" 4,9 [El diablo] le llevó a Jerusalén y le puso en el alero del templo y le dijo: “Si eres Hijo de Dios, tírate abajo. ${ }^{4,10}$ Pues está escrito: Dará órdenes a sus ángeles sobre ti ${ }^{4,11}$ y te tomarán en sus manos, para que tu pie no tropiece con la roca". 4,12 Y Jesús le [respondió] diciendo: "Está escrito: No pondrás a prueba al Señor, tu Dios". ${ }^{4,5}$ Y el diablo lo llevó a un monte [muy alto] y le mostró todos los reinos del mundo y su gloria, 4,6 y le dijo: “Todo esto te lo daré ${ }^{4,7}$ si te postras ante mí". 4,8 Y Jesús le [respondió] diciendo: "Está escrito: Ante el Señor, tu Dios, te postrarás y solo a él le darás culto". ${ }^{4,13}$ Y el diablo le dejó.

Tras las palabras de Juan anunciando la llegada de un personaje misterioso para realizar el juicio de Dios (Q 3,7-17) se introduce a un nuevo actor, Jesús, quien acude adonde Juan para ser bautizado (Q 3,21-22) ${ }^{50}$, y, tras esto, será llevado al desierto para ser tentado (Q 4,1-13). La entrada en

50 No todos los autores están de acuerdo con que el bautismo formase parte del Documento Q. Cf. Fleddermann, Q: A Reconstruction, 233-235, sostiene que no existía en $Q$ dicha escena. La razón que da se apoya en que el autor de $Q$ decidió contar la historia de Jesús mediante discursos, y no hallamos en la obra ningún otro evento de su vida descrito como el bautismo. Además, la inclusión del bautismo rompería la estructura anular de la primera parte de $Q(Q 3,7-7,35)$. Otros abogan por su posible existencia, como Guijarro Oporto, Los dichos, 42, o Kloppenborg, The Formation, 85. Estos autores defienden que tal escena no estorba ni molesta en el desarrollo de Q. Esta es también mi opinión: puede ser que Mt y Lc tomasen el relato del bautismo de Jesús de Mc, pero esto no es razón suficiente para afirmar que $Q$, tan semejante a Mc en su comienzo, no contuviera uno. La reconstrucción de Q 3,21-22 (escena del bautismo de Jesús) es dificultosa y sus resultados son fragmentarios. Aun así, su existencia es plausible por varios motivos: ¿por qué llama el diablo Hijo de Dios a Jesús (Q 4,3), si antes no ha sido llamado así? Pudiera deberse a un conocimiento de la identidad verdadera de Jesús por su condición de criatura del ámbito cósmico, pero, dentro de la historia que narra $Q$, pienso que el lector comprende mejor el uso de este título si ya antes fue atribuido a Jesús, como ocurre en Q 3,22. Por otro lado, está también el motivo del Espíritu: para el lector es más fácilmente comprensible que el Espíritu guíe a Jesús al desierto (Q 4,1) si este antes ha aparecido en escena. Además, debido a que una de las propiedades atribuidas a "el que ha de venir" es bautizar con Espíritu, es tan lógico que se le asigne por parte de Dios (Q 3,21-22), revelando así la identidad de ese misterioso personaje anunciado por Juan $(Q 3,16 b)$, como que lo posea directamente. Todo esto me lleva a concluir que la escena del bautismo en $Q$ no solo no molesta, sino que ayuda en el desarrollo de la trama. 
escena de Jesús propicia el comienzo del "nudo". Normalmente, como sucede en este caso, es la porción más amplia de la obra. Aquí es donde se producen los diversos intentos de resolver la tensión iniciada en el momento desencadenante, que en $\mathrm{Q}$, como antes se indicó, tiene que ver con la identidad del juez, la realización del juicio y las consecuencias que esto tiene para el pueblo de Israel.

Creo que ambos pasajes, bautismo y tentaciones, forman una única escena, o al menos están tan intrínsecamente ligados que tiene más sentido estudiarlos juntos por varios motivos. El primero es que todos los escenarios donde se sitúa la acción, y que conforman su marco narrativo (la región del Jordán, el desierto, Jerusalén, un monte), están enlazados con la historia de Israel; otro tiene que ver con el papel que juegan las fuerzas cósmicas en ambas escenas: Dios, que derrama el Espíritu sobre Jesús y le llama "hijo", y el diablo, que le tienta y le reconoce como Hijo de Dios; junto con esto también se observa la personificación del Espíritu (que no se vuelve a producir en Q) y la utilización del título "Hijo de Dios" en ambas.

Mientras Jesús es bautizado acaece un acto sobrenatural que excede el significado del rito que Juan practica: se abren los cielos (Q 3,21) y el Espíritu viene sobre Jesús (Q 3,22). Siguiendo la lógica del relato, Juan recibe en este momento la confirmación de su revelación ${ }^{51}$ : Dios ha enviado un juez, al que se le entrega el Espíritu con que bautizará a Israel (al menos a aquellos que produzcan frutos de conversión, como dice Q 3,8.17). Se da a entender entonces que Jesús tiene asignado un papel en el inminente drama escatológico que Juan ha profetizado (Q 3,7), y se responde a la expectativa que se ha suscitado en la escena anterior: ¿quién es "el que ha de venir"? Este es Jesús. Pero la resolución de este suspense genera otra intriga mayor, ya que suscita la curiosidad de saber cómo es y cómo actuará Jesús, algo que ya se empieza a resolver en la escena que sigue (Q 4,1-13).

A continuación, el Espíritu conduce a Jesús del Jordán al desierto para ser tentado (Q 4,1). A través de las respuestas que Jesús da a las distintas pruebas que le va planteando el diablo se empieza a perfilar la identidad del que a todas luces parece ser el encargado de realizar lo anunciado por Juan. En la primera tentación se usa un motivo ya conocido por el lector: el poder de Dios para sacar de las inertes piedras hijos de Abrahán

51 A mi modo de ver, que Juan sea testigo de este evento ayuda a entender mejor su desconcierto más adelante $(Q 7,18-23)$, cuando la actuación de Jesús no se adecua a la imagen que el propio Juan tiene de ese agente divino según la revelación que ha recibido. 
$(\mathrm{Q} 3,8)$. Ahora este argumento es esgrimido por el diablo para que Jesús demuestre su condición divina convirtiéndolas en pan (Q 4,3). Con su respuesta, Jesús no solo rechaza la tentación, sino que además enseña cómo "las necesidades materiales no deben estar a la cabeza de la lista de prioridades del hombre" 52 .

En la segunda tentación se da un paso más. Jesús muestra cómo no hay que poner a prueba a Dios $(\mathrm{Q} 4,12)$. Esto es algo que constantemente Israel ha hecho a lo largo de su historia y que puede explicar el que Dios se haya cansado y haya decretado un juicio para extirpar lo estéril del pueblo $(\mathrm{Q} 3,9)$. El centro de esta tentación es la petición de un signo, no para el beneficio de otros (Q 7,22), sino para la gloria personal del que lo hace; se anticipa así un tema que luego se va a retomar y va a servir para desvelar al frente opositor: la petición de un signo por parte de "esta generación" (Q 11,16). Con su actitud, Jesús manifiesta la ambigüedad que los signos poseen y cómo pedirlos se convierte en algo demoníaco y opuesto al plan de Dios manifestado en la Escritura.

La respuesta a la tercera tentación constituye el clímax de la escena. Jesús indica cuál es el camino correcto del hombre: postrarse ante Dios y darle culto (Q 4,8). Esta es la única vía de salvación ante el juicio que se avecina de manera inminente. El discurso que sigue (Q 6,20b-49) clarificará, al estilo de los profetas (Is 58,1-12), el contenido de ese culto debido a Dios, donde la opción por Dios y por su enviado, el Hijo de Dios, parece ser el único camino. Si tomamos la escena de las tentaciones en su conjunto, Jesús aparece como el Hijo obediente a Dios que actúa siguiendo su dictado. Es, por tanto, el adecuado para manifestar al pueblo de Israel el camino de la salvación, ya que muestra cuál es la actitud necesaria para llegar a la conversión y gloriarse de ser hijo de Dios (Q 3,8).

Las escenas del bautismo y las tentaciones suponen un gran avance en el desarrollo de la narración, porque se va clarificando, sin llegar a resolverse del todo, la identidad de "el que ha de venir" - no su modo de actuar, del que nada se dice aún-, que se revela como el Hijo obediente de Dios. También se señala que la obediencia filial es la actitud que debe apropiarse el que desee dar fruto ${ }^{53}$. Ahora que sabemos que Jesús es "el que ha de venir", se espera que muestre cómo va llevar a cabo su tarea, tal y cómo Juan había anunciado (Q 3,16b-17), manteniéndose viva la tensión narrativa de la historia.

52 TUCKETT, "The Temptation Narrative".

53 Guijarro Oporto, Los dichos, 42: “Esta presentación de Jesús [el bautismo y las tentaciones] prepara al lector para escuchar su enseñanza". 


\subsubsection{Sermón inaugural de Jesús}

\section{$Q 6,20 b-49$}

${ }^{20}$ [...] Y levantando sus [ojos hacia] sus discípulos dijo: “Dichosos los pobres, porque [vuestro] es el reino de Dios. 21 Dichosos los que tenéis hambre, porque [seréis] saciados. Dichosos los [que estáis afligidos], porque [seréis consolados]. ${ }^{22}$ Dichosos vosotros cuando os insulten y os [persigan] y digan [contra] vosotros [toda clase de] maldades por causa del Hijo del hombre. ${ }^{23}$ Alegraos y [exultad], porque vuestra recompensa será grande en el cielo; pues así [persiguieron] a los profetas anteriores a vosotros. ${ }^{27}$ Amad a vuestros enemigos ${ }^{28}$ [y] orad por los que os [persiguen], ${ }^{35 c d}$ así seréis hijos de vuestro Padre, que hace salir su sol sobre malos y [buenos y envía la lluvia sobre justos e injustos]. ${ }^{29}$ [A quien te abofetee] en la mejilla, preséntale también la otra; y [al que te quiera llevarte a juicio para quitarte] la túnica, [dale] también el manto. Y si alguien te obliga a acompañarle una milla, ve con él dos. ${ }^{30}$ Al que te pide, dale; y [a quien te pida prestado,] no le reclames [lo tuyo]. ${ }^{31}$ Tratad a los demás como queráis que ellos os traten a vosotros. ${ }^{39}$ ¿Acaso puede un ciego mostrar el camino a otro ciego? ¿No caerán los dos en el hoyo? ${ }^{40}$ Un discípulo no está por encima del maestro. [Le basta al discípulo llegar a ser] como su maestro. ${ }^{41}$ ¿Cómo es que ves la mota que hay en el ojo de tu hermano y no te das cuenta de la rama que hay en tu propio ojo? ${ }^{42}$ ¿Cómo puedes decir a tu hermano: 'Deja que saque la mota [de] tu ojo', mientras tienes la rama en tu propio ojo? Hipócrita, saca primero la rama de tu ojo y entonces podrás ver claramente para sacar la mota del ojo de tu hermano. ${ }^{43}$ [...] No hay árbol bueno que dé fruto malo ni [tampoco] árbol malo que dé fruto bueno. ${ }^{44} \mathrm{El}$ árbol se conoce por el fruto. ¿Acaso se cosechan higos de los espinos o uvas de los abrojos? ${ }^{45}$ El hombre bueno saca cosas buenas del tesoro bueno, y el [hombre] malo del mal [tesoro] saca cosas malas, pues de la abundancia del corazón habla [su] boca. ${ }^{46}$ ¿Por qué [...] me llamáis: 'Señor, Señor', y no hacéis lo que digo? ${ }^{47}$ Todo aquel que escucha mis palabras y las pone en práctica ${ }^{48}$ se parece a un hombre que edificó [su] casa sobre la roca; cayó la lluvia, vinieron las riadas, [soplaron los vientos] y sacudieron aquella casa, pero no se derrumbó, porque estaba cimentada sobre la roca. ${ }^{49} \mathrm{Y}$ [todo] el que escucha [mis palabras] y no [las] pone en práctica se parece a un hombre que edificó [su] casa sobre la arena; cayó la lluvia, vinieron las riadas, [soplaron los vientos] y sacudieron aquella casa, y enseguida se derrumbó, y fue muy grande su [ruina]".

Tras las tentaciones se produce un cambio de escenario. Jesús se traslada a Nazará o a las afueras de Cafarnaún ${ }^{54}$. Al margen de donde dis-

${ }^{54}$ La localización de este discurso de Jesús (Q 6,20b-49) es difícil de ubicar en un lugar concreto. Nazará $(Q 4,16)$ es un texto que pertenece a la categoría de textos de dudosa reconstrucción, y esto le convierte en un tema discutido. Como señala KLoPPEnBoRG, $Q$ Parallels, 22: “Alguna forma de transición es requerida entre Q 4,13 y Q 6,20b, que ha quedado oscurecida por la actividad redaccional de Mt y Lc, y por lo tanto su reconstrucción es extremadamente especulativa". Independiente- 
curra la acción, la importancia recae en lo que el contenido de esta aporta a la intriga. Una vez identificado el personaje a quien Juan anunció (Q 3,16b) con Jesús, lo lógico sería el comienzo del juicio. En cambio, nos encontramos con algo totalmente distinto, no solo en su forma, sino también en su contenido.

La escena nos muestra a Jesús pronunciando un discurso ante una muchedumbre ${ }^{55}$. Esta exhortación arranca con una promesa de felicidad (Q 6,20b-23) cuyo contenido es muy innovador, porque cuestiona tanto el legalismo como la solidaridad tradicional ${ }^{56}$. Jesús propone "una transformación de las actitudes que rigen las relaciones con los demás, basadas no ya en la respuesta proporcional, que era el modelo de la ley del talión, sino poniendo por norma una desproporción inspirada en la misericordia y la

mente del lugar, se hace necesario un cambio de escenario; se pasa de un marco cósmico, donde se desarrollan las tentaciones, a uno histórico, donde se va a desarrollar la actividad de Jesús para que el pueblo de Israel pueda ser testigo de su actuación. Por tanto, es plausible localizarla en cualquiera de los dos lugares; a favor del primero tenemos el dato histórico de que Jesús era llamado "Nazareno"; así pues, no es descabellado pensar que allí comenzase su actividad, y que por este motivo este topónimo sea adjuntado a su nombre; quizá haya que incluir también dentro de esta hipótesis el dato que conserva también Mc de la falta de acogida que Jesús encuentra allí $(6,1-6)$, dato que está en consonancia con $Q 7,9$, donde se informa de la falta de fe de Israel. A favor de las afueras de Cafarnaún tenemos Q 7,1, donde se dice que, tras terminar estas palabras (referidas a $Q$ 6,20b-49), Jesús entró allí. Dejando aparte la discusión sobre la ubicación exacta del discurso jesuano, ambos datos sirven para sostener la hipótesis, ampliamente difundida entre muchos investigadores, de que $Q$ fue escrito en Galilea (GUIJARRo OporTo, Los dichos, 95-99; ReEd, El Jesús de Galilea, 115-146; VAAGE, Galilean Upstarts).

${ }_{55}$ Creo que, conforme al hilo narrativo, sería más apropiada la lectura de $\mathrm{Mt} 5,1$, donde Jesús está rodeado de una gran muchedumbre, que la lucana (recogida por la edición crítica de Q), donde Jesús se dirige solo a sus discípulos. La razón, aparte de la opinión de algunos autores, que señalan que la mención de los discípulos como únicos receptores de las palabras de Jesús posiblemente se deba a la pluma de Lucas (Fitzmyer, El Evangelio según Lucas. II, 591), es que el descubrimiento por parte del lector de que Jesús tiene discípulos y que se dirigiera solo a ellos es más inteligible en $Q$ 10,2-11,3 (preparado por Q 9,57-60, que es una escena vocacional que hace de marco narrativo a toda la composición) que ahora. Como apoyo a esta postura está también el hecho de que más adelante $(Q 7,24)$ Jesús se dirija a la muchedumbre (se usa el acusativo plural de ojlos en $M t 5,1$ y Q 7,24), lo que hace preguntarse al lector de dónde ha salido esta multitud. Esto no es óbice para que entre esta multitud que le escucha haya "futuros" discípulos de Jesús, que, tras oírle, deciden hacerse sus seguidores $(Q 9,57-60)$. Pero, una vez más, debido a la peculiar naturaleza de $Q$, es totalmente plausible la lectura que recoge la edición crítica que estamos usando.

56 Miquel Pericás, “Del movimiento”, 108-113. 
acogida incondicional que se revelan en el modo de actuar de Dios" ${ }^{57}$. Lo que predomina en el discurso es la admonición a no ser ciego (Q 6,39.4142) y a dar fruto bueno (Q 6,43-45). Por tanto, lo que aquí se desarrolla es el motivo de la última oportunidad que Dios ofrece antes del inminente desenlace (Q 3,7-9).

Sorprende que, tras el anuncio de la llegada de "el que ha de venir", la única referencia que encontremos sobre su faceta judicial en este discurso sea (Q 6,37). Donde se pone el acento es en que Dios, a través de Jesús, llama a su pueblo a la conversión; y lo hace de una manera radicalmente novedosa; es una invitación a la felicidad y a la dicha que se ofrece en nombre del Padre, lejos de ser una respuesta por el temor al castigo. Se observa cómo se ha dado un paso más en el desarrollo de la trama explicitando en qué consiste la oferta de salvación de Dios contenida en la escueta declaración "dar buen fruto" (Q 3,9). También se ha desvelado que Jesús es el agente enviado por Dios para ofertar su última propuesta, todo ello en el contexto del juicio ante el que Israel tiene que comparecer. Pero el lector se pregunta dónde han quedado las duras palabras de Juan y, más aún, si es Jesús "el que ha de venir", cuando su actuar parece decir lo contrario.

\subsubsection{Juan, Jesús y esta generación}

$Q 7,18-19.22-23$

18 Juan [al oír hablar de todas estas cosas], envió a algunos de sus discípulos ${ }^{19}$ [para preguntar]le: “ ¿Eres tú el que ha de venir o hemos de esperar a otro?" 22 Y él les respondió: "Id y contadle a Juan lo que estáis viendo y oyendo: los ciegos recobran la vista, los cojos caminan, los leprosos son purificados, los sordos oyen, los muertos resucitan y a los pobres se les anuncia la buena noticia. ${ }^{23} \mathrm{Y}$ dichoso el que no se escandalice de mí".

Las “cosas" (Q 7,18) de Jesús causan sorpresa en Juan; la razón es sencilla: no es lo que él esperaba. En la narración de la actuación de Jesús no se encuentran los elementos de amenaza y castigo, talar $(\mathrm{Q} 3,9)$ y quemar (Q 3,9.17), que hacen patente la cólera de Dios (Q 3,7); sus palabras son más una propuesta de felicidad que un reproche por los pecados cometidos ante la llegada del juicio divino. Esto crea el suspense necesario que hace al lector adherirse a la pregunta que Juan plantea por boca de sus discípulos: ¿es Jesús "el que ha de venir”, el juez que Dios iba a enviar?

57 Guijarro Oporto, Los dichos, 46. 
$(Q 7,19)^{58}$. Hasta ahora parece que Jesús es el portador de esa última oportunidad que Dios da a Israel. Quizá, como piensa Juan, haya que esperar a otro $(\mathrm{Q} 7,19)$ que venga después a finalizar la obra de Dios, el juicio sobre el pueblo; la intriga crece por medio del suspense, la trama se complica y se hace necesario un desenlace: es capital para ello el papel que juega este diálogo (Q 7,18-19.22-23).

Contrariamente a lo esperado, la respuesta de Jesús no es todo lo clara que uno podría desear; él, ni lo afirma ni lo niega, sino que contesta haciendo un elenco de actos salvadores anunciados por las Escrituras (Q 7,22-23) y que ya ha realizado ${ }^{59}$, constituyendo uno de los ejemplos más claros que juegan los gaps (lagunas) dentro de la narración ${ }^{60}$. Estas actuaciones van más encaminadas a mostrar su papel salvador que forense (como juez) ${ }^{61}$, ya que estos eventos son parte de los actos escatológicos en los cuales Dios actúa $^{62}$.

Se hace evidente que esta respuesta tampoco está todavía en consonancia con las expectativas suscitadas por Juan. Él anunciaba un juicio y una llamada a la conversión (Q 3,7-9), pero no la llegada de alguien que realizará un ministerio salvador a favor de los más desfavorecidos de Israel. Entonces, ¿hay que esperar a otro personaje que realice el juicio? ¿No es Jesús el juez esperado y anunciado? La respuesta que se da es tajante: "Dichoso el que no se escandalice de mí" (Q 7,23); así, las expectativas del lector se ponen en crisis y, al igual que Juan y sus discípulos, es invitado a cambiar, o al menos a ampliar su mirada. La intriga se mantiene por medio de la sorpresa, ya que se ha revelado algo que ocasiona que se modifique el modo de comprender a Jesús y su ministerio: que Dios ha enviado un verdadero salvador para restaurar la humanidad caída y a los caídos de la humanidad. El uso nuevamente del título ho erjómenos incide en esta línea de invitación a cambiar de punto de vista y a corregir las expectativas; se debe pasar del temor a la ira divina (Q 3,7) a la apertura para acoger esa salvación que ha llegado, "lo que estáis viendo y oyendo" (Q 7,22), lo que Jesús ha hecho y dicho, que demuestra que él es "el que ha de venir".

58 MeIer, Un judío marginal. II/l, 179.

59 Is 26,$19 ; 29,18 ; 35,5-6 ; 42,7 ; 61,1$.

60 Cf. GenetTe, Figures III, 72, que habla de "paralipsis", llamando así a los datos sobre los que el relato pasa y que luego son llenados de una manera retrospectiva. Así, aunque no ha sido relatado ningún milagro de Jesús, el lector, a través de sus palabras, es capaz de imaginar un ministerio dilatado y fructífero a favor de los más desfavorecidos.

${ }^{61}$ Joseph, “Blessed”, 320.

62 También el juicio de Dios es un evento escatológico, pero de él nada dice Jesús. 
${ }^{24}$ Cuando estos se marcharon comenzó a hablar a la gente acerca de Juan: ¿¿Qué salisteis a ver en el desierto? ¿Una caña zarandeada por el viento? ${ }^{25}$ Entonces, ¿qué salisteis a ver? ¿Un hombre vestido lujosamente? Mirad que quienes llevan vestidos lujosos están en los palacios de los reyes. ${ }^{26} \mathrm{En}$ tonces, ¿qué salisteis a ver? ¿Un profeta? Yo os digo que sí, y más que un profeta. ${ }^{27}$ Este es aquel de quien está escrito: 'He aquí que yo envío mi mensajero por delante de ti, el cual preparará tu camino ante ti'. ${ }^{28}$ Yo os digo: no ha surgido de entre los nacidos de mujer uno mayor que Juan; pero el más pequeño en el reino de Dios es mayor que él. ${ }^{29}$ [porque vino a vosotros Juan (...) los publicanos y (...) le creyeron] ${ }^{30}$ [pero las autoridades religiosas lo rechazaron]. ${ }^{31}$ ¿A qué compararé esta generación? ¿A qué [se] parece? ${ }^{32} \mathrm{Se}$ parece a unos niños sentados en [la] plaza, que provocan [a otros] diciendo: 'Os hemos tocado la flauta y no habéis bailado; hemos entonado endechas y no habéis llorado'. ${ }^{33}$ Porque vino Juan, que no comía ni bebía, y decís: 'Tiene un demonio'. ${ }^{34}$ Y vino el Hijo del hombre, que come y bebe, y decís: 'Es un comilón y un borracho, amigo de publicanos y pecadores'. ${ }^{35}$ Pero la sabiduría es justificada por sus hijos".

La historia avanza desapareciendo de escena los discípulos de Juan. La afirmación tajante de Jesús (Q 7,23) ha provocado un aumento de la intriga por medio de la curiosidad, ya que, si Jesús no es el anunciado por Juan, ¿es el Bautista entonces un falso profeta y, por tanto, queda invalidada su predicación? Más aún, ¿se ha arrepentido Dios y no se va a producir el juicio anunciado? Jesús toma de nuevo la palabra y elimina esta duda: Juan no solo no es un falso profeta, sino que es el profeta esperado (Q 7,27) y el más grande de los nacidos de mujer $(\mathrm{Q} 7,28)$. Al ser presentado como profeta se resuelve la cuestión sobre la procedencia de su conocimiento de la situación actual y futura $(\mathrm{Q} 3,7-9)^{63}$. La información sobre la identidad de Juan identifica aún más a Jesús como "el que ha de venir", puesto que Juan es "el que es enviado por delante" (Q 7,27), mientras que este misterioso personaje era "el que venía detrás" de Juan (Q 3,16b) ${ }^{64}$.

Jesús indica cómo Juan ha sido fiel y ha cumplido su tarea, que es ir delante preparando el camino $(\mathrm{Q} 7,27)$ de "el que ha de venir" que inaugura la nueva etapa del reino de Dios $(\mathrm{Q} 7,22)$. La labor de Juan es la de preparar y no la de pregonar el reino; así se descarta que Juan sea un falso profeta y, al resituar su papel, se induce a corregir las expectativas que creó

${ }^{63}$ Q 7,24-25 nos ofrece una descripción de Juan bastante enigmática. Para ver las diversas teorías sobre el significado de esta descripción, MEIER, Un judío marginal. II/I, 183-192.

${ }^{64}$ La cita de la Escritura (Mal 3,1), como en el caso de las tentaciones (Q 4,4.8.12), sirve a Jesús de apoyo para aclarar su identidad. 


\section{EL CARÁCTER NARRATIVO DEL DOCUMENTO Q}

su anuncio (Q 3,16b-17). Siguiendo el hilo de la comparación entre su misión y la de Juan (Q 7,33-34), Jesús llama la atención sobre la falta de fe y el desconcierto en que siguen sumidos algunos, a los que denomina "esta generación" (Q 7,31). Queda así patente que rechazar a Juan y a Jesús supone dar la espalda a la oferta de salvación a la que Dios llama, anunciada por Juan y explicitada por Jesús ${ }^{65}$.

Esta escena, que adopta la forma de discurso de Jesús, tiene la función de identificar y clarificar tanto su identidad como la de Juan y sus respectivas misiones. A la vez señala la falta de acogida que han experimentado sus propuestas por parte de "esta generación". Se produce una complicación más en el "nudo" que suscita la curiosidad del lector, haciendo avanzar la intriga: ¿qué suerte le espera y quienes son los denominados como "esta generación"?Y todavía sigue pendiente si va a producirse el juicio inminente, que parece que puede tener alguna vinculación con la acogida y el rechazo de Jesús y su misión (Q 7,31-35).

\subsubsection{Discipulado y misión}

Q9,57-11,13

9,57 Uno le dijo: "Te seguiré adondequiera que vayas". 9,58 Y Jesús le dijo: "Las zorras tienen madrigueras y los pájaros del cielo, nidos, pero el Hijo del hombre no tiene donde reclinar la cabeza". 9,59 Otro le dijo: "Señor, permíteme que vaya primero a enterrar a mi padre". 9,60 Y él le dijo: "Sígueme y deja que los muertos entierren a sus propios muertos". ${ }^{10,2}$ Dijo a sus discípulos: "La mies es abundante, pero los trabajadores son pocos. Rogad, pues, al Señor de la mies para que mande trabajadores a su mies. ${ }^{10,3}$ ¡Poneos en camino! Mirad que os envío como ovejas en medio de lobos. ${ }^{10,4}$ No llevéis [bolsa], ni alforja, ni sandalias, ni bastón; y no saludéis a nadie por el camino. ${ }^{10,5}$ En la casa en que entréis decid [primero]: 'Paz [a esta casa]'. ${ }^{10,6}$ Y si allí hay un hijo de paz, que vuestra paz venga sobre él. Y, si no, que vuestra paz [vuelva a] vosotros. ${ }^{10,7}$ Quedaos [en esa casa], comiendo y bebiendo lo que tengan, pues el trabajador merece su salario. [No vayáis de casa en casa]. ${ }^{10,8} \mathrm{Y}$ en la ciudad en que entréis y os reciban, [comed lo que os pongan] ${ }^{10,9}$ y curad a los enfermos que haya en ella, y decid[les]: 'El reino de Dios ha llegado a vosotros'. ${ }^{10,10}$ En la ciudad en que entréis y no os reciban, salid fuera [de ella] ${ }^{10,11}$ y sacudid el polvo de vuestros pies. ${ }^{10,12}$ Os digo que aquel día será más llevadero para Sodoma que para esa ciudad. ${ }^{10,13}$ ¡Ay de ti, Corozaín! ¡Ay de ti, Betsaida!; porque si los portentos realizados en voso-

${ }^{65}$ La relación entre salvación y sabiduría que subyace a esta declaración de Jesús $(Q 7,35)$ está tomada de la Escritura, aunque no usando una cita directa, sino la idea que está en Prov 8,32-36. 
tras se hubieran realizado en Tiro y en Sidón, hace tiempo que se habrían convertido con saco y ceniza. ${ }^{10,14}$ Por eso el día del juicio será más llevadero para Tiro y Sidón que para vosotras. ${ }^{10,15} Y$ tú, Cafarnaún, ¿acaso te elevarás hasta el cielo? Bajarás hasta el infierno. ${ }^{10,16} \mathrm{El}$ que os recibe a vosotros me recibe a mí, [y] el que me recibe a mí recibe al que me ha enviado".

${ }^{10,21}$ En aquel tiempo dijo: “Te doy gracias, Padre, Señor del cielo y de la tierra, porque has ocultado todas estas cosas a los sabios e inteligentes y se las has revelado a los sencillos. Sí, Padre, porque así te ha parecido bien. 10,22 Todo me lo ha entregado mi Padre, y nadie conoce al Hijo sino el Padre, y tampoco conoce al Padre nadie sino el Hijo, y aquel a quien el Hijo se lo quiera revelar. ${ }^{10,23}$ Dichosos los ojos que ven lo que veis [...] ${ }^{10,24}$ Pues os digo que muchos profetas y reyes desearon ver lo que vosotros veis y no lo vieron, y oír lo que vosotros oís y no lo oyeron. ${ }^{11,2 b}$ [Cuando] oréis, [decid]: 'Padre, que tu nombre sea santificado; que venga tu reino. ${ }^{11,3}$ Danos hoy el pan necesario; ${ }^{11,4}$ y perdónanos nuestras deudas, como nosotros perdonamos a los que nos deben; y no nos pongas en tentación'. 11,9 Yo os digo: pedid y se os dará, buscad y encontraréis, llamad y se os abrirá. ${ }^{11,10}$ Porque todo el que pide recibe, el que busca encuentra y al que llama se le abrirá. ${ }^{11,11}$ [...] ¿Quién de entre vosotros, si su hijo le pide pan, le dará una piedra? ${ }^{11,12}$ ¿0 si le pide un pez le dará una serpiente? ${ }^{11,13}$ Pues si vosotros, siendo malos, sabéis dar cosas buenas a vuestros niños, ¿cuánto más vuestro Padre del cielo dará cosas buenas a quienes le piden?"

Encontramos en esta escena ${ }^{66} \mathrm{y}$ en la que sigue (Q 11,14-51) un desarrollo de un tema ya incoado en la tercera tentación ${ }^{67}$ : que solo se puede estar o con Dios o con el demonio. Al ser identificado Jesús con el Hijo de Dios, la elección entre aceptar y rechazar a Jesús es semejante a decidir si dar culto a Dios o al demonio; optar por Jesús es optar por Dios. Aquí se explicitan las consecuencias de estar con Jesús, que son llevar a cabo su misma misión, curar a los enfermos de las casas donde entren y decirles a sus moradores que el reino de Dios ha llegado a ellos (Q 10,9). Esta tarea no se puede realizar si no se adopta el modo de vida de Jesús; de igual modo que el Hijo del hombre no tiene donde reclinar la cabeza (Q 9,58), los discípulos deben realizar su servicio a la intemperie (Q 10,3-4) y sabiendo que, si Jesús fue rechazado (Q 10,13-15), ellos también pueden serlo

${ }^{66}$ En mi opinión, abarca $Q 9,57-11,13$, pero no hay un acuerdo unánime. Por ejemplo, KLoppenBorg, The Formation, 92, separa Q 9,57-10,23 de Q 11,2-13, lo mismo que JaCOBSon, The First Gospel, 77-250; mientras que GuIJARro Oporto, Los dichos, 50, o Fleddermann, $Q$ : A Reconstruction, 112, las agrupan. Yo me decanto es este trabajo por esta última opción, al entender que las enseñanzas sobre la oración van unidas íntimamente a las misioneras como claves para la vida discipular.

67 TUCKETT, “The Temptation Narrative", 506. Como acertadamente señala el autor, "la colocación del relato de las tentaciones al comienzo de la historia proporciona al lector una importante clave hermenéutica para lo que sigue". 
(Q 10,10-12). Es interesante notar cómo el tema del rechazo va asociado al juicio; si hasta ahora no se habían especificado las consecuencias por no acoger la actuación de Jesús (Q 7,31-35), a partir de este momento este tema va a ir ganando en explicitud (Q 10,14.11,31-32.51).

Es la primera vez que se asocia de forma tan explícita el reino de Dios con la persona de Jesús. Es cierto que en Q 7,28 se hablaba de la novedad introducida por "el que ha de venir", e incluso podría deducirse que esta novedad era el reino de Dios; pero solo ahora se afirma sin ambages que la llegada del reino de Dios está vinculada a la tarea de Jesús y de los discípulos enviados en su nombre (Q 10,16); ellos son los sencillos que, a través de Jesús, han conocido al Padre (Q 10,21-22), al que se pueden dirigir con confianza (Q 11,2b-4) y, de esta manera, han adquirido también el estatus de hijos (Q 11,13). El discípulo no solo participa de la misión de Jesús, sino también de su relación filial, por eso puede tratar a Dios como Padre (Q 11,2b). Se pone en contraste la acogida de Jesús con la pertenencia a la descendencia de Abrahán (Q 3,8); solo la primera es la filiación verdadera que causa la salvación.

La función de esta perícopa es ir resolviendo el suspense sobre la recepción de la oferta salvadora de Dios manifestada por Jesús. Hasta el momento parecía que tal acogida era para Jesús un deseo (Q 7,23); solo ahora se ha hecho realidad tangible en aquellos que han conocido al Padre y al Hijo, que trae la salvación en su nombre. La cuestión pendiente es si la acogerán todos. La siguiente escena responde a esta pregunta y, de paso, indica cuál es el destino que aguarda a los duros de corazón.

\subsubsection{Acusación y respuesta de Jesús}

Q 11,14-51

${ }^{14}$ Expulsó un demonio mudo y, una vez expulsado el demonio, el mudo habló, y la gente se quedó admirada. ${ }^{15}$ Algunos decían: "Con el poder de Belcebú, príncipe de los demonios, expulsa los demonios". ${ }^{17}$ Sabiendo lo que pensaban, les dijo: "Todo reino dividido internamente queda devastado, y toda casa dividida internamente no podrá subsistir. ${ }^{18} Y$ si Satanás está dividido internamente, ¿cómo podrá subsistir su reino? ${ }^{19} Y$ si yo expulso los demonios con el poder de Belcebú, vuestros hijos, ¿con qué poder los expulsan? Por eso ellos serán vuestros jueces. ${ }^{20}$ Pero si yo expulso los demonios con el dedo de Dios, entonces es que el reino de Dios ha llegado a vosotros. ${ }^{21}$ [La casa de un hombre fuerte no puede ser saqueada]. ${ }^{22}$ [Pero si otro más fuerte le vence, será saqueado]. ${ }^{23}$ El que no está conmigo está contra mí; y el que no recoge conmigo desparrama. ${ }^{24}$ Cuando el espíritu inmundo sale de una persona, deambula por lugares áridos buscando descanso, pero no 
lo encuentra. [Entonces] dice: 'Volveré a mi casa de donde salí'. ${ }^{25}$ Y al regresar la encuentra barrida y limpia. ${ }^{26}$ Entonces va y trae consigo otros siete espíritus peores que él, y entra para quedarse a vivir allí. Y la situación final de aquella persona es peor que la del principio". ${ }^{16}$ Algunos [...] le pedían un signo. ${ }^{29}$ Y [él dijo:]: “Esta generación es una generación [...] mala; pide un signo, pero no se le dará otro signo que el signo de Jonás. ${ }^{30}$ Pues así como Jonás fue un signo para los ninivitas, así [también] el Hijo del hombre lo será para esta generación. ${ }^{31}$ En el día del juicio, la reina del Sur se levantará contra esta generación y la condenará, porque vino desde los confines de la tierra para escuchar la sabiduría de Salomón, y aquí hay algo mayor que Salomón. ${ }^{32}$ En el día del juicio, los habitantes de Nínive se levantarán contra esta generación y la condenarán, porque se convirtieron por la predicación de Jonás, y aquí hay algo mayor que Jonás. ${ }^{33}$ Nadie enciend[e] una lámpara y la pone [en un lugar oculto], sino sobre el candelero, [y alumbra a todos los que están en la casa]. La lámpara del cuerpo es el ojo. Si tu ojo está sano, todo su cuerpo [está] iluminado. Pero si tu ojo es malo, todo tu cuerpo está a oscuras. ${ }^{35} \mathrm{Y}$ si la luz que hay en ti es oscuridad, iqué grande la oscuridad!

42 Ay de vosotros, fariseos, que pagáis el diezmo de la menta, del eneldo y del comino, pero [descuidáis] la justicia, la misericordia y la fidelidad. Estas cosas habría que hacer sin descuidar aquellas. ${ }^{39 b}$ Ay de vosotros, fariseos, que purificáis por fuera la copa y el plato, pero por dentro estáis llenos de rapiña y ambición. ${ }^{41}$ [Purificad] el interior de la copa [...] y [...] su exterior [...] puro. ${ }^{46 \mathrm{~b}}[\mathrm{Y}$ ] ay de vosotros, [maestros de la Ley], que [atáis] pesados fardos [...] [y los colocáis sobre las espaldas de los demás, pero] vosotros no movéis un dedo para [llevar]los. ${ }^{52}$ Ay de vosotros, [maestros de la Ley], que cerráis [el reino (de Dios) para los demás]. Ni entráis vosotros [ni] dejáis entrar a los que quieren entrar. ${ }^{47}$ Ay de vosotros, que edificáis los sepulcros de los profetas, aunque vuestros padres los mataron. ${ }^{48}$ [...] dais [testimonio contra vosotros mismos de que sois hijos] de vuestros padres [...] ${ }^{49}$ Por eso también la Sabiduría [...] dijo: 'Les enviaré profetas y sabios, y a algunos de ellos los matarán y perseguirán', ${ }^{50}$ de modo que se le pedirá cuentas a esta generación de la sangre de todos los profetas derramadas desde el comienzo del mundo. ${ }^{51}$ Desde la sangre de Abel hasta la sangre de Zacarías, que pereció entre el altar y la morada. Sí, os lo aseguro, se le pedirá cuentas a esta generación.

En estrecho paralelismo con la escena anterior, ahora se va a explicitar quiénes son y qué les sucede a los que rechazan a Jesús (Q 11,23), quienes, según la interpretación que obtenemos del relato de las tentaciones, sirven al demonio. No se indica que los discípulos estén presentes, aunque los adversarios de Jesús también serán los suyos cuando él no esté (Q 12,11-12) ${ }^{68}$.

${ }^{68}$ Quizá esta escena juegue el mismo papel que el relato del martirio de Juan Bautista en el evangelio de Marcos (6,14-29): dar tiempo a los discípulos para realizar la misión que Jesús les encomienda. De ahí que se pueda deducir su ausencia de esta agria disputa entre Jesús y sus adversarios, aunque también se puede argumentar su presencia silenciosa, como en Mc 2,23-28. 
Comienza la escena con la realización de un exorcismo, única alusión de esta actividad de Jesús en Q. Como en la curación del chico del centurión (Q 7,1-9), se busca dirigir la atención del lector no al hecho portentoso, sino a la actitud de los participantes en el diálogo (Q 11,15-20). Entre los que lo contemplan hay algunos que rechazan a Jesús, acusándolo de ser un demonio, agente de Belcebú (Q 11,15) ${ }^{69}$. A dicha acusación él responde con varios argumentos (Q 11,17-20), entre los que destaca el último, la oposición existente y consabida entre Dios y el demonio; este tema ya conocido (Q 4,1-13) es ahora utilizado por Jesús para explicar a los que le rechazan cuál es la fuente de su poder (Q 11,20). Finaliza esta argumentación con una advertencia (Q 11,23) que traslada al lector al comienzo de la obra y que le sirve para percatarse de la diferencia existente entre la labor de Jesús y sus discípulos y la de sus adversarios ${ }^{70}$.

El uso nuevamente del pronombre indefinido tìs en plural (Q11,15.16) da pie a observar quiénes son y cuál es el destino que aguarda a los que han aparecido en escena oponiéndose a Jesús. Ahora Jesús se refiere a ellos como "esta generación" (Q 11,29), expresión usada ya anteriormente para describir a los que rechazaban su actividad y la de Juan (Q 7,31). Estos solicitan un signo a Jesús, pero él apunta hacia sí mismo (el Hijo del hombre) como el signo final. Esto hace que se mantenga la tensión narrativa por medio de la sorpresa. La comparación con Jonás (Q 11,30) presenta su misión en términos de "llamada a la conversión", como ya Juan había anticipado (Q 3,9.17). Desoír esta llamada desemboca en la condenación, como ahora explicita el mismo Jesús (Q 11,31-32).

¿A quién se refiere Jesús cuando emplea esta denominación tan genérica de "esta generación" y que aparece en la narración como sus oponentes? Hay que descartar que la expresión equivalga al pueblo entero de Israel, porque algunos se han hecho sus discípulos y están colaborando con él (Q 9,57-11,13); el texto señala a dos grupos judíos específicos: los fariseos (Q 11,42-44) y los maestros de la Ley (Q 11,46b-48.52) ${ }^{71}$. Se les

69 De nuevo aparece el tema de la ambigüedad de los signos que ya quedó indicada en el relato de las tentaciones (cf. TUCKETT, "The Temptation Narrative", 500) y que se retomará un poco más adelante $(Q 11,16)$.

70 El uso del verbo synágô en ambos casos parece aludir a la labor de "el que ha de venir" $(Q 3,17)$, en la cual ya están colaborando sus discípulos $(Q 10,2)$, pero no así los adversarios que desparraman (Q 11,23).

71 No solo los datos de la crítica histórica conceden verosimilitud a esta identificación (GuiJarro Oporto, Los dichos, 95-99, o TucketT, $Q$ and the History, 438-450), sino que la misma narración lo confirma: estos son los sabios e inteligentes a los que Dios ha ocultado estas cosas, la revelación de Jesús $(Q 10,21)$. 
acusa de ser los causantes de la desgracia de todo el pueblo (Q 11,52), siguiendo el camino iniciado por sus padres, quienes rechazaron la llamada de Dios a la conversión a través de profetas y sabios (Q 11,49), a quienes acabaron persiguiendo y asesinando (Q 11,47.49) ${ }^{72}$. Ellos tendrán que dar cuenta en el juicio por esta sangre derramada (Q 11,50-51), además de por su contumaz impenitencia (Q 11,31-32). Al ser presentado Jesús al lado de los profetas y sabios parece que el relato nos quiere señalar el final que le aguarda.

Se halla aquí la conclusión de uno de los hilos narrativos del relato, el referente a cómo se va a posicionar Israel ante el juicio inminente anunciado por Juan y su llamada a la conversión. Queda claro que no todo Israel está perdido, porque algunos han acogido a Jesús como el agente por medio del cual Dios ofrece la salvación para escapar del juicio. Este grupo experimentará rechazo y dificultades (Q 10,10-12), pero debe confiar en el Dios providente, que Jesús ha revelado y que les ha aceptado como hijos (Q 10,21-11,13). Otros, sin embargo, persisten en el camino hacia su perdición al continuar imitando al antiguo Israel, que también rechazó las anteriores ofertas salvadoras de Dios (Q 11,47.49.51).

En relación con la temática sobre la actuación judicial de "el que ha de venir" (Q 3,16b-17) se produce una transformación. Se establece una conexión directa entre la persona de Jesús y el juicio, haciendo que dependa de su aceptación o rechazo la salvación o condena de cada uno. Se produce así un avance significativo en la intriga narrativa al afirmar sin ambages, y no indirectamente ${ }^{73}$, la existencia de un juicio ante el que hay que

72 Caracterizado como "sabiduría" $(Q 11,49)$ al igual que en $(Q 7,35)$.

${ }^{73}$ Ya anteriormente Jesús se ha identificado con el Hijo del hombre $(Q$ 6,22; $Q 7,34)$. Si también él es "el que ha de venir" $(Q 3,16 \mathrm{~b})$, como ha quedado claro en Q 7,23, ahora, con esta declaración, asocia a esta figura el título de Hijo del hombre. Llamo la atención sobre esto por el significado que tiene este título en el desarrollo de la intriga de Q. BROAdHEAD, Naming, 124-134, hace un análisis de este título dentro del evangelio de Marcos partiendo del contexto histórico y literario que lo rodea (de ahí que, aunque sus investigaciones no se refieran directamente a $Q$, nos sirven para clarificar el significado y alcance de dicho título). Dice el autor que en el desarrollo tradicional de esa figura están las imágenes que hablan del Hijo del hombre como juez futuro, cuando despliegue su poder; el Hijo del hombre es una figura autoritativa cuyo futuro viviente está marcado por el poder, la gloria y el juicio. Esto no es óbice para que dicha autoridad se haga ya patente, puesto que el Hijo del hombre es Jesús. Este título no es confesional en el evangelio de Marcos, ya que solo es usado por Jesús en la narración y nunca es puesto en boca de otros. Este mismo uso y valor lo hallamos en $\mathrm{Q}$. Dicho título ayuda al desarrollo de la trama, porque conecta la figura de "el que ha de venir" con el Hijo del hombre, ambos personajes con un cierto cariz futuro y ambos asociados al rol judicial. 


\title{
EL CARÁCTER NARRATIVO DEL DOCUMENTO Q
}

comparecer, como ya lo anunció Juan, y en el que Jesús, el Hijo del hombre, juega un papel decisivo. Todo esto ocasiona un aumento de la tensión narrativa que prepara la resolución del suspense; ahora que se han tomado posturas ante Jesús y este ha llevado a cabo la labor para la que había venido (Q 7,22), solo cabe esperar la llegada del juicio de Dios (Q 3,7).

\subsubsection{Revelación de lo escondido}

Q 12,39-40

\begin{abstract}
39 Sabed esto: si el dueño de la casa supiera a qué hora de la noche va a llegar el ladrón, no le permitiría hacer un boquete en su casa. ${ }^{40}$ Estad vosotros también preparados, porque a la hora que menos penséis llega el Hijo del hombre.
\end{abstract}

A diferencia de las composiciones precedentes, esta no posee un marco narrativo tan acentuado. Esta va a ser la tónica general de las agrupaciones de materiales que vamos a encontrar en la parte final del Documento (excepto quizá Q 17,20-19,26, agrupación que tiene un claro tenor escatológico y cuyo centro es la venida del Hijo del hombre). Por eso, a partir de ahora, el análisis estará más centrado en pequeñas perícopas que en algunas perícopas concretas, para intentar dilucidar la continuidad de la intriga. En esta parte final de Q hay sobre todo enseñanzas que instan a la perseverancia en el seguimiento y la misión con vistas a la parusía, circunscritas a la tarea misional, que se confía a los discípulos en este nuevo tiempo que se abre con la partida de Jesús $(\mathrm{Q} 12,40)^{74}$.

Ya se advirtió que la intriga se preparaba para su resolución; ahora va a estar centrada en el tema de la venida del juicio y su agente. Es entonces el momento de que se produzca la "acción transformadora" o "clímax" donde se resuelva completamente la trama. En este caso no se trata de un momento concreto, sino de un proceso de cambio que consiste en la asunción por Jesús del papel de juez y en la revelación del tiempo del juicio.

Jesús, al presentarse como el Hijo del hombre, asume el papel que sus contemporáneos atribuían a esa figura, y por tanto hace que el lector u oyente caiga en la cuenta de que, al ser el Hijo del hombre, el juicio no ha sido descartado (como podría ser la impresión sacada de su actuación hasta este momento), sino que sigue vigente. Para una exposición más pormenorizada, véase FleddermanN, Q: A Reconstruction, 130-143.

74 Guijarro Oporto, Los dichos, 59. 
Este dicho (Q 12,39-40) hace avanzar esta temática por medio de la sorpresa. Jesús habla de la llegada del Hijo del hombre. Esto asombra al lector. Hasta ahora el relato solo ha usado el título de Hijo del hombre para referirse a Jesús, y solo aparece en su boca para revelar su identidad, por eso se descarta que pueda estar refiriéndose a otro personaje distinto. Si él ya está aquí, entonces la pregunta que surge es: ¿a qué se refiere cuando habla de su llegada? ¿Acaso se va a ir a algún sitio? Eso es lo que parece dar a entender la insistencia de Jesús a sus discípulos en la vigilancia.

\section{$Q 12,49.51 .53$}

49 [He venido a arrojar fuego sobre la tierra, y cómo desearía que hubiera prendido ya]. ${ }^{51}$ [¿Pen]sáis que he venido a arrojar paz sobre la tierra? No he venido a arrojar paz, sino espada. ${ }^{53} \mathrm{He}$ venido a dividir al hijo contra el padre, [y] a la hija [contra] su madre, [y] a la esposa [contra] su suegra.

Por primera vez en la narración que Jesús declara abiertamente que él es el juez esperado. La referencia a su labor de arrojar fuego transporta al lector inmediatamente a la apertura del relato, único otro lugar donde se menciona este elemento. "El que ha de venir" bautizará con fuego $(\mathrm{Q} 3,16 \mathrm{~b})$ y quemará la paja en un fuego inextinguible $(\mathrm{Q} 3,17)^{75}$; Jesús reclama ahora para sí el rol de juez, que Juan había asociado a este personaje $(\mathrm{Q} 3,16 \mathrm{~b})$. Acorde con esto está el papel de dividir que Jesús se atribuye en Q 12,53, correspondiente a la labor de separar que realizará "el que ha de venir" (Q 3,17).

Esta perícopa, junto con la anterior (Q 12,39-40), supone un gran progreso para la intriga, aunque no la resuelve del todo; mientras que se solventa el tema de la identidad del juez se ha introducido un nuevo elemento en la trama que suscita la curiosidad manteniendo vivo el suspense: ¿cuándo va ejercitar Jesús ese papel? Porque hasta ahora ninguna de sus actuaciones ha estado encaminada a esta labor de condenación que Juan atribuía a "el que ha de venir". Además, todo indica (Q 12,2-17,6) que los discípulos van a tomar su relevo como continuadores de su actuación salvífica en nombre de Dios. Pero, por otro lado, Jesús ha anunciado que esta labor se llevará a cabo cuando vuelva; es legítimo preguntarse a qué se refiere Jesús con su partida y cuándo esta se va a producir.

75 Aunque Q 12,49 es un versículo discutido, la mayoría de los autores están a favor de su inclusión en $Q$, KLoPPEnBorg, Q Parallels, 142. 


\subsubsection{Entrar por la puerta estrecha}

\section{Q 13,34-35}

34 Jerusalén, Jerusalén, que mata a los profetas y apedrea a los que le son enviados. Cuántas veces he querido reunir a tus hijos, lo mismo que la gallina reúne a sus polluelos bajo sus alas, y no habéis querido. ${ }^{35}$ Por eso se os quitará vuestra casa. Os [...] digo que no me veréis hasta [que llegue el momento en que] digáis: "Bendito el que viene en nombre del Señor".

La denominada "lamentación sobre Jerusalén" (Q 13,34-35) juega un papel esencial en la trama de $\mathrm{Q}$, puesto que resuelve de una manera definitiva la tensión dramática del relato. La perícopa tiene un claro "tenor escatológico"76; Jesús, como portavoz divino, se lamenta por el rechazo de Jerusalén de las distintas ofertas de salvación que Dios ha presentado (Q 13,34), incluida esta última ofrecida por él mismo. Ya se sabe por la narración que el rechazo de Israel de aquellos que le han sido enviados ha sido violento (Q 11,49-51). Estos datos inducen al lector a pensar que Jesús puede estar hablando a sus discípulos de su muerte ${ }^{77}$. Así se confirma en lo que sigue: "Ya no me veréis" (Q 13,35), lo que supone la desaparición de Jesús, que se va a producir porque va a sufrir la misma suerte que el resto de los enviados de Dios ${ }^{78}$.

Junto al anuncio de su muerte está también el de su vuelta (Q 13,35), resolviéndose así totalmente la intriga y poniendo el punto final a la tensión narrativa del relato. Jesús ha predicho su vuelta (Q 12,40), porque va

76 Robinson, “The Saying Gospel”, 363.

77 Desde mi punto de vista, la perícopa ofrece los suficientes indicios para afirmar que habla sobre la muerte de Jesús. Por un lado está la aparición de Jerusalén, que hasta ahora solo había sido nombrada en otra ocasión $(Q 4,9)$. Esta referencia para mí no es casual, sino que está vinculada a su pasión, como lo confirma la alusión a la muerte de los profetas y de los que le son enviados por Dios (cf. Fleddermann, “The Plot”, 52, aunque él dice que es en Q 4,9 donde se produce una prolepsis de la pasión que constituye la revelación que resuelve la intrigal. Todo esto me lleva a pensar que la muerte es el destino que Jesús va a correr, ya que, como ha quedado patente a lo largo del relato, él es un enviado por Dios (Q 7,34-35); más aún: es su Hijo (Q 4,1-13). Además, esto explicaría de forma adecuada las instrucciones dadas a los discípulos que pueblan este final del documento, las cuales cobran mayor sentido a raíz de su desaparición.

78 La explicación de la muerte de Jesús de esta manera coincide con la teología deuteronomista, que, como ya se indicó, estaba también presente en la predicación de Juan. Esto explicaría que Q no tenga necesidad de un "Relato de la pasión", ya que su muerte se justifica según la forma típica de la tradición deuteronomística (véase JACOBSON, “The Literary Unity”, 386). 
a ser ejecutado en Jerusalén. Este no será su fin, ya que Dios lo exaltará y volverá de nuevo como ho erjómenos en nombre del Señor ${ }^{79}$. Se colma así la tensión iniciada en el "momento desencadenante" (Q 3,7-17), a la vez que se resuelve una de las complicaciones planteadas en el "nudo", vinculada a la pregunta de Juan $(Q 7,19)$. Jesús es "el que ha de venir"; primero, ha venido ejerciendo el papel de aquel que llama a la conversión ofreciendo la salvación de Dios (Q 6,20b-49; Q 7,22), por cuyo rechazo o aceptación se decide el destino de las personas (Q 11,31-32; 12,8-9); y, después, tras su muerte y exaltación, volverá y ejercerá como el Hijo del hombre que viene a juzgar (Q 12,49; Q 13,34-35; Q 17,26-27.30.34-35) ${ }^{80}$.

Esta perícopa cierra el proceso correspondiente a la "acción transformadora" de la trama, donde se ha confirmado la existencia de un juicio, se ha revelado la identidad del juez y el lector ya ha sido informado de lo que tiene que hacer para salvarse. La exaltación de Jesús tras su muerte es la que le confiere la potestad para llevar a cabo el juicio, que solo tendrá lugar con su segunda venida ${ }^{81}$.

\subsubsection{Discurso escatológico}

Q 17,20-35

20 [Preguntado sobre cuándo vendría el reino de Dios, les respondió diciendo: “El reino de Dios no vendrá aparatosamente]. ${ }^{21}$ [Y no dirán: ‘ $¡$ Mirad, aquí está!' 0: ‘ ¡Allí está!' Porque el reino de Dios está dentro de vosotros]. ${ }^{23} \mathrm{Si}$ os dicen: ¡Mirad, está en el desierto!' No salgáis. ¡Mirad, está dentro de casa!’ No vayáis detrás. ${ }^{24}$ Porque así como el relámpago brilla desde occidente hasta oriente, así aparecerá el Hijo del hombre [en su día]. ${ }^{37}$ Donde está el cadáver, allí se reunirán los buitres. ${ }^{26}$ [Como sucedió en los] días de Noé,

79 No hay acuerdo unánime sobre si la exaltación de Jesús en $Q$ hay que entenderla como resurrección (Fleddermann, "The Plot", 52-60) o como glorificación (SMITH, The Post-Mortem). Es ajeno al interés de este trabajo la forma en la que $Q$ entiende la exaltación de Jesús; lo que interesa es que, tras ella, Jesús asume el papel de juez.

80 Schürmann, "The Son of Man”, en Kloppenborg (ed.), The Shape of Q, 94. Como he dicho, ya en su ministerio terreno (Q 12,49.51.53), Jesús se identificó como juez, aunque solo desempeñará su papel en su segunda venida.

81 Como afirma Foster, “The Pastoral Purpose", 91: “El destino de Israel y de todo hombre queda ligado por su respuesta al ho erjómenos". SMITH, The Post-Mortem, 112: "Su tarea terrena se convierte, por tanto, en una demostración de su futura capacidad". Ambas afirmaciones confirman la potestad que le será conferida a Jesús tras su muerte (Q 13,34-35). 


\section{EL CARÁCTER NARRATIVO DEL DOCUMENTO Q}

así será [en el día] del Hijo del hombre. ${ }^{27}$ [Pues así como en aquellos días] comían y bebían, se casaban y se entregaban en matrimonio, hasta el día en que Noé entró en el arca, y llegó el diluvio y se los llevó a todos, ${ }^{30}$ así será también en el día en que el Hijo del hombre se manifieste. ${ }^{34}$ Os lo aseguro: estarán dos [en el campo]; a uno se lo llevarán y a otro lo dejarán. ${ }^{35}$ Estarán dos moliendo en el molino; a una se la llevarán y a otra la dejarán".

Tras colmarse la tensión narrativa de la obra viene la "conclusión" o "situación final", donde se describen los efectos de la acción transformadora y el nuevo estado que de ellas se deriva. Esta es la función que cumplen tanto esta perícopa como la siguiente.

Una vez que ya Jesús se ha revelado como el juez y ha clarificado el momento de su actuación, ahora ahonda en la explicación de lo que esta supone. Usando la figura del Hijo del hombre, a la que tradicionalmente se le atribuye este papel judicial, Jesús anuncia su repentina futura manifestación (Q 17,23-24) para cumplir la tarea de juzgar (Q 17,34-35). La referencia de llevarse a unos y dejar a otros se adecua perfectamente al papel que Juan atribuía a "el que ha de venir" (Q 3,17), siendo así una pista más para ayudar al lector a asociarlo a este personaje anunciado con Jesús. Es aquí donde más se explicita la vinculación del Hijo del hombre con el juicio ${ }^{82}$.

\section{$Q 22,28.30$}

${ }^{28}$ [...] Vosotros, los que me habéis seguido ${ }^{30}$ [...] os sentaréis sobre tronos para juzgar a las doce tribus de Israel.

Q 22,28.30 responde adecuadamente al momento de la "situación final" en la que ha desembocado la acción llevada a cabo en el relato. No todo Israel es ahora una raza de víboras (Q 3,7); hay algunos, los que han seguido a Jesús (Q 22,28), que han dado los frutos de conversión exigidos $(\mathrm{Q} 3,8)$. Estos son los discípulos que han perseverado en la llamada que recibieron al seguimiento de Jesús (Q 9,47-50), y que no solo serán salvados en el juicio, sino que compartirán la potestad del juez (Q 22,30) al igual que compartieron su suerte y misión en la tierra ${ }^{83}$. Se supone que junto con ellos estarán todos los que han seguido a Jesús a través de la misión que los discípulos deben desarrollar en el tiempo que se da entre la partida de Jesús

82 Fleddermann, Q: A Reconstruction, 834-835: “El día del Hijo del hombre se refiere al juicio, que Dios no ha cancelado".

${ }^{83}$ No es desacertado afirmar que si el discípulo que ha permanecido fiel comparte en todo la suerte de Jesús, también compartirá la tarea cuando la exaltación del Hijo se produzca. Así parece indicarlo Q 22,28.30. 
y su vuelta. Esta última escena viene a confirmar que el juicio es uno de los principales hilos narrativos de la trama de $\mathrm{Q}$.

\section{Resultados del estudio}

Se ha querido poner de manifiesto cómo la trama de Q se adecua a la definición de trama como "proceso dramático", ya que un episodio genera una expectativa en el lector que es confirmada o corregida por el siguiente, de tal manera que solo al final se puede estar en posesión de la plenitud de sentido $^{84}$. Tras este análisis, donde se ha querido mostrar la existencia de una intriga narrativa en Q que confirma el carácter narrativo de esta obra, es legítimo preguntarse si esta trama encaja dentro de algún modelo de los propuestos por los investigadores de la narratología. El anterior estudio muestra que podemos ubicar la trama de Q dentro de la categoría de las "unificadoras". En este tipo de intriga, todos los episodios son pertinentes para el relato (cada episodio descansa en el que le precede y prepara el que le sigue) y tienen una relación con el resultado de los acontecimientos contados. También se descubre que esta trama es una intriga de "revelación", ya que los acontecimientos tienen una función ilustrativa, subordinada al personaje.

Uniéndome a las intuiciones de otros autores que han ido apareciendo a lo largo de estas páginas, pienso que se puede sostener el carácter narrativo de Q; como se ha querido exponer en este trabajo, parece claro que esa es la intención del redactor final por el material recogido y su disposición ${ }^{85}$.

\footnotetext{
84 Ricoeur, Para una teoría, 123.

${ }^{85}$ Aunque no tiene que ver directamente con el presente estudio, me parece adecuado preguntarse si se puede ubicar el Documento $Q$ dentro de algún género narrativo de la antigüedad. Existen estudios precedentes que lo señalan. Destacan entre ellos el de Kloppenborg (The Formation, 263-328, sobre todo 325-328, donde las similitudes entre la redacción final de $Q$ y obras de carácter biográfico, como Los dichos de Ahikar, La vida de Esopo o Demonax, de Luciano de Samosata, le llevan a afirmar que $Q$ es una protobiografía de Jesús) y sobre todo el de Downing ("A Genre of Q"), quien, tomando como base los estudios de Burridge (What Are the Gospels?), es el que llega a unas conclusiones más firmes. Partiendo de todos aquellos esos que Burridge señala como propios de una obra biográfica de la antigüedad, y que le llevan a concluir que los evangelios son "biografías" de Jesús; y, por otro lado, comparando el Documento $Q$ con otras biografías antiguas, como Demonax, de Luciano de Samosata o La vida de Diógenes, de Laercio (estudio similar al estudio comparativo que Burridge hace entre los evangelios y estas obras), este autor concluye que $Q$ tiene un prólogo semejante a la obra de Luciano de Samosata (sería la predicación de Juan en Q 3,2b-17); un protagonista que es el sujeto de la mayor parte de los verbos que focalizan la atención en ese personaje; un
} 
Si otros defienden este carácter apoyados en los elementos que descubren en $\mathrm{Q}^{86}$, este estudio ha querido ir un paso más allá. La narratividad de Q no viene solo porque $\mathrm{Q}$ contenga elementos con carácter narrativo o incluso algún relato (como en el caso de las tentaciones), sino que lo fundamental es que posee una intriga que se manifiesta a través de los recursos del suspense, la curiosidad y la sorpresa.

Esta trama que se revela en $\mathrm{Q}$ tiene una secuencia narrativa donde los sucesos se encadenan en un orden cronológico (elemento esencial para poder hablar de la existencia de un relato $)^{87}$. Dicha secuencia arranca con el ministerio del Bautista (Q 3,2b-17), continúa con la aparición en escena y presentación de Jesús (Q 3,21-4,13); tras ella viene el desarrollo del ministerio de Jesús (Q 6,20b-49; 7,18-35), en el que algunos colaboran en un segundo momento $(\mathrm{Q} 9,57-11,13)$ mientras que otros lo rechazan $(\mathrm{Q} 11,14-51)$; sigue el anuncio de la futura venida de Jesús con poder y las enseñanzas de los discípulos para este tiempo intermedio (Q 12,39-40; 49-53; 13,34-35; $17,20-35)$ y finaliza con el anuncio de la recompensa que aguarda a los que le han seguido $(\mathrm{Q} 22,28.30)^{88}$.

Tal secuencia narrativa, con su marcado acento temporal, se corresponde bastante bien con el esquema de la trama. Así encontramos en Q los elementos necesarios para su construcción ${ }^{89}$ : Q 3,2b-17 constituye la "situación inicial" y el "momento desencadenante" de la acción, correspondiente a la actuación de Juan; Q 3,21-4,13 es el comienzo del "nudo" con la aparición en escena de Jesús; Q 12,39-40; 12,49.51.53; 13,34-35 se corresponden con la acción transformadora: en este caso, el de un proceso donde se alcanza el clímax de la revelación de la identidad de Jesús y de su misión; Q 17,20-35 y 22,28.30 son la situación final, resultado de esta acción transformadora. Así, se puede concluir que encontramos en Q los elementos fundamentales que se necesitan para hablar de trama, que a su vez es, como ya se ha afirmado, la esencia del relato.

recorrido vital del personaje lque, como en otras biografías antiguas, no está tan centrado en hechos históricos, como su nacimiento o muerte, sino en sus actitudes); una serie de características externas (estructura, extensión, unidad literaria, método de caracterización) e internas (escenarios, tópicos, estilo); todo esto, unido a la flexibilidad constatada de los géneros literarios en la antigüedad, le lleva a concluir al autor la cercanía existente entre $Q$ y las biografías de los filósofos cíni$\cos y$, por lo tanto, que $Q$ pertenecería a dicho género biográfico.

\footnotetext{
86 Fleddermann, Q: A Reconstruction, 106.

87 Ricoeur, Para una teoría, 127.

88 A esta conclusión también parece llegar SLOAN, "Q as a Narrative Gospel”, 1-22.

89 Marguerat - Bourquin, Cómo leer los relatos bíblicos, 78.
} 


\section{Bibliografía}

Álvarez Cineira, D., "El Documento Q. En busca del grupo perdido", Estudios Eclesiásticos 82 (2007) 491-551.

Allison JR., D. C., The Jesus Tradition in Q, Harrisburg 1997.

BABUT, J.-M., Un tout autre christianisme: traduction nouvelle et commentaire de la Source Q, Paris 2010.

Broadhead, E. K., Naming Jesus. Titular Christology in the Gospel of Mark, Sheffield 1999.

Bultmann, R., Historia de la tradición sinóptica, Salamanca 2000.

Burridge, R. A., What Are the Gospels? A Comparison with Graeco-Roman Biography, Grand Rapids 1992.

Chatman, S., Story and Discourse. Narrative Structure in Fiction and Film, New York 1978.

Colinas Blanco, J., ó épxó 2016 [inédito]; Biblioteca de la Universidad Pontificia de Salamanca, VZ. Tesina/T 947, 44-70.

Delgado Jara, I., Gramática griega del Nuevo Testamento. II. Sintaxis, Salamanca 2011.

Downing, F. G., "A Genre for Q, and a Socio-Cultural Context for Q: Comparing Sets of Similarities and Differences", JSNT 55 (1994) 3-26.

-, "Quite Like Q: A Genre for 'Q': The 'Lives' of Cynic Philosophers", Biblica 69 (1988) 196-225.

Fitzmyer, J. A., El Evangelio según Lucas, Madrid 1987-2005.

Fleddermann, H. T., "The Plot of Q", EThL 88 (2012) 43-69.

-, Q: A Reconstruction and Commentary (Biblical Tools and Studies 1), Leuven 2005.

Foster, P., “The Pastoral Purpose of Q's Two-Stage Son of Man Christology", Biblica 89 (2008) 81-91.

Genette, G., Figures III, Paris 1972.

Goodacre, M., The Case against Q. Studies in Markan Priority and the Sinoptic Problem, Harrisburg 2002.

GuiJarro Oporto, S., Los cuatro evangelios (BEB 124), Salamanca 2010.

-, Los dichos de Jesús. Introducción al Documento Q (BEB 144), Salamanca 2014.

Hurtado, L. W., Señor Jesucristo. La devoción a Jesús en el cristianismo primitivo, Salamanca 2008.

JaCobson, A. D., The First Gospel. An introduction to Q, Sonoma 1992.

-, "The Literary Unity of Q", JBL 101 (1982) 365-389. 
Joseph, S. J., "Blessed is Whoever is not Offended by Me: The Subversive Appropiation of Royal Messianic Ideology in Q3-7", New Testament Studies 57 (2011) 308-324.

Kloppenborg, J. S., Excavating Q. The History and Setting of the Saying Gospel, Minneapolis 2000.

-, The Formation of Q. Trajectories in Ancient Wisdom Collections, Minneapolis ${ }^{2} 2000$.

-, Q Parallels. Synopsis, Critical Notes and Concordance, Sonoma 1998.

Marguerat, D. - Bourquin, Y., Cómo leer los relatos bíblicos. Iniciación al análisis narrativo (Presencia Teológica 106), Santander 2000.

McLean, B. H., "On the Gospel of Thomas and Q", en R. A. Piper (ed.), The Gospel behind the Gospels. Current Studies on Q, Leiden 1995, 321-345.

MeIER, J. P., Un judío marginal. Nueva visión del Jesús histórico. II/I, Estella ${ }^{4} 2008$.

Miquel Pericás, E., "Del movimiento de Jesús al grupo de Q. Un estudio sobre la localización social de la moral", en S. Guijarro Oporto (ed.), Los comienzos del cristianismo, Salamanca 2006, 93-115.

NeIRYNCK, F., "Q: from Source to Gospel”, Ephemerides Theologicae Lovaniensis 71 (1995) 166-175.

PARK, I., "Children and Slaves: The Metaphors of Q", en D. T. Roth - R. Zimmermann - M. Labahn (eds.), Metaphor, Narrative and Parables in $Q$ (WUNT 315), Tübingen 2014, 73-91.

ReED, J. L., El Jesús de Galilea, Salamanca 2006.

Ricoeur, P., Para una teoría del discurso narrativo, Barcelona 1999.

Robinson, J. M., "The Saying Gospel Q", en F. NeIRYnck (ed.), The Four Gospels (BEThL 71), Leuven 1995, 361-388.

Robinson, J. M. - Hoffmann, P. - Kloppenborg, J. S., The Critical Edition of Q. Synopsis Including the Gospels of Matthew and Luke, Mark and Thomas with English, German and French Translations of $Q$ and Thomas, Leuven 2000.

Rollens, S. E., "Conceptualizing Justice in Q: Narrative and Context", en D. T. Roth - R. Zimmermann - M. Labahn (eds.), Metaphor, Narrative and Parables in $Q$ (WUNT 315), Tübingen 2014, 93-113.

Santos Otero, A. DE, Los evangelios apócrifos, Madrid 2009.

Schürmann, H., "The Son of Man Title in the Sayings Source", en J. S. KLOPPEnborg (ed.), The Shape of Q. Signal Essays on the Sayings Gospel, Minneapolis 1994, 74-97.

SKA, J.-L., Nuestros padres nos contaron. Introducción al análisis de los relatos del Antiguo Testamento (Cuadernos Bíblicos 155), Estella 2012. 
Ska, J. L. - Sonnet, J.-P. - Wénin, A., Análisis narrativo de relatos del Antiguo Testamento (Cuadernos Bíblicos 107), Estella 2001.

SlOAN, D. B., "Q as a Narrative Gospel", en http://www.davidbsloan.com, 1-22 (consultado: 17 de octubre de 2015).

Smith, D. A., The Post-Mortem Vindication of Jesus in the Sayings Gospel $Q$ (Library of New Testament Studies 338), New York 2007.

Tuckett, C. M., "The Existence of Q", en R. A. PiPer (ed.), The Gospel behind the Gospels. Current Studies on Q, Leiden 1995, 19-47.

-, $Q$ and the History of Early Christianity, New York 1996.

-, "Scripture and Q", en ID. (ed.), The Scriptures in the Gospels (BEThL 131), Leuven 1997, 3-26.

-, "The Temptation Narrative in Q", en F. van Segbroeck (ed.), The Four Gospels. Festschrift Frans Neirynck (BEThL 100), Leuven 1992, 479-507.

Uro, R., "John the Baptist and the Jesus Movement", en R. A. PIPER (ed.), The Gospel behind the Gospels. A Current Studies of Q, Leiden 1995, 231-257.

VaAge, L. E., Galilean Upstarts. Jesus' First Followers According to $Q$. Pennsylvania 1994.

WénIn, A., La historia de José, «Génesis 37-50» (Cuadernos Bíblicos 130), Estella 2006.

Williams, J. G., "Parable and Chreia: From Q to Narrative Gospel", Semeia 43 (1988) 85-114.

ZERWICK, M., El griego del Nuevo Testamento (Instrumentos para el Estudio de la Biblia II), Estella 2009.

(recibido: 01/07/17 - aceptado: 01/09/17) 